\title{
Lung transplantation: challenges in the COVID-19 era, a narrative review of the literature
}

\author{
Francisco Gregorio Alvarez-Aquino, Sadia Shah
}

Mayo Clinic, Jacksonville, FL, USA

Contributions: (I) Conception and design: Both authors; (II) Administrative support: None; (III) Provision of study materials or patients: None; (IV) Collection and assembly of data: Both authors; (V) Data analysis and interpretation: None; (VI) Manuscript writing: Both authors; (VII) Final approval of manuscript: Both authors.

Correspondence to: Francisco Gregorio Alvarez-Aquino. Mayo Clinic, Jacksonville, FL, USA. Email: alvarez.franciscog@mayo.edu.

\begin{abstract}
The severe acute respiratory syndrome coronavirus 2 pandemic poses unique challenges for lung transplant recipients. The optimal management of these patients is not known and the risk of transmission of the SARS-CoV-2 during lung transplantation is a major concern. Clear guidelines for selection of lung transplant candidates due to chronic pulmonary disease due to COVID-19 are urgently needed. The objective of this study is to review the available evidence on the diagnosis and treatment of the coronavirus disease 2019 in lung transplant recipients, as well as current recommendations regarding the screening of potential organ donors and recipients and the implementation of the COVID-19 vaccine in patients both on the waitlist and after lung transplantation. We performed an electronic search of the literature in the PubMed, MedRxiv COVID-19 SARS-Cov-2, LitCovid-NCBI-NLM-NIH, and Medline databases, From December 2019 to January 22, 2021. The following keywords with and without Boolean operators were used: "covid-19", "SARS-CoV-2" in combination with "lung transplantation", "solid organ transplant", and "immunosuppression". Articles in the English and Spanish languages were extracted. Web sites of the Center for Disease Control (CDC), International Society for Heart \& Lung Transplantation, National Institute of Health, Infectious Diseases Society of America (IDSA), and the Federal Drug Administration were reviewed. A total of 168 reports and websites references were used for this review. Lung transplant recipients with COVID-19 are at increased risk for severe illness and death. Management should be similar as the general population but immunosuppression must be adjusted. Lung transplant recipients should receive the COVID-19 vaccine 2 to 3 months after transplantation. Extreme care must be taken to precent transmission of the SARS-CoV-2 during transplantation. The number of patients with post COVID-19 chronic respiratory failure referred for lung transplantation is expected to increase in the near future. There is much to be known regarding the management of lung transplant recipients with COVID-19. Protocols are needed to prevent transmission of the SARS-CoV-2 during transplantation and clear guidelines are needed to define the criteria for lung transplant in patients with residual severe pulmonary disease post COVID-19 infection.
\end{abstract}

Keywords: Lung transplantation; COVID-19; SARS-CoV-2

Received: 30 October 2020; Accepted: 05 March 2021; Published: 25 August 2021.

doi: $10.21037 /$ ccts-20-172

View this article at: http://dx.doi.org/10.21037/ccts-20-172

\section{Introduction}

In December 2019, a novel coronavirus, the severe acute respiratory syndrome coronavirus 2 (SARS-CoV-2), emerged in the city of Wuhan, China, and spread to the entire world as one of the most lethal pandemics in recent history. The World Health Organization (WHO) designated the disease caused by this virus as COVID-19 on February 11, 2020 (1), and on March 11, 2020 declared 
COVID-19 as a pandemic (2).

Although most patients have a benign course, 14\% may present with severe disease and $5 \%$ with a critical illness (3), characterized by a cytokine release syndrome (CRS) and multiorgan failure, including adult respiratory distress syndrome (ARDS) with respiratory failure (4) and death (5). Risks factors associated with severe illness and death include age 65 or older, and the presence of co-morbidities like obesity, diabetes, underlying cardiac, renal or liver disease, and immunosuppressed state.

On June 25, 2020 the Center for Disease Control (CDC) added solid organ transplants recipients (SOTr) to the list of "strongest and most consistent evidence" of high risk population (6). This is not surprising as many of the mentioned risk factors are usually present in this population, along with vulnerability from immunosuppressive regimens that specifically target the T-cell immunity, which plays a vital role in viral clearance. Although limited by the small number of reported cases, the outcome data for SOTr with COVID-19 is variable with some evidence suggesting increased risk of severe disease and mortality (7-13), although others have reported outcomes similar to the general population (14-17). SARS-CoV-2 infection presents additional challenges for lung transplant recipients (LTxR), not only in terms of initial morbidity and mortality of a virus that directly targets the allograft, but also for the potential long term sequelae, including an increased risk of subsequent development of chronic allograft dysfunction (CLAD), as described following infections by other respiratory viruses (18-20).

In this review we will summarize the available evidence regarding COVID-19 and its impact in LTxR, including:

(I) Clinical presentation;

(II) Diagnosis;

(III) Treatment in LTxR:

(i) Ambulatory management;

(ii) Management of hospitalized patients;

(iii) Follow up after hospital discharge.

(IV) Screening of donors and recipients;

(V) The decision to proceed with transplantation;

(VI) Reactivation of patients on the waitlists after SARS$\mathrm{CoV}-2$ infection;

(VII) Lung transplantation for SARS-CoV-2 chronic respiratory failure recipients;

(VIII) Vaccination for patients in the waitlist or post lung transplantation.

We present the following article in accordance with the Narrative Review reporting checklist (available at https:// ccts.amegroups.com/article/view/10.21037/ccts-20-172/rc).

\section{Methods}

We performed an electronic search of the literature in the PubMed, MedRxiv COVID-19 SARS-Cov-2, LitCovid-NCBI-NLM-NIH, and Medline databases, From December 2019 to January 22, 2021. The following keywords with and without Boolean operators were used: "covid-19", "SARS-CoV-2" in combination with "lung transplantation", "solid organ transplant", and "immunosuppression". Articles in the English and Spanish languages were extracted. Web sites of the Center for Disease Control (CDC), International Society for Heart \& Lung Transplantation, National Institute of Health, Infectious Diseases Society of America (IDSA), and the Federal Drug Administration were reviewed.

\section{Clinical presentation}

The typical symptoms of COVID-19 have been well established (21), and include cough, fever, dyspnea, myalgias, fatigue, gastrointestinal symptoms, headaches, anosmia and dysgeusia. Table 1 describes most common clinical presentation for LTxR with proven COVID-19 compared with the general population and other SOTr. Based on a compilation of several reports $(7,11,12,14,22-31)$, It appears that dyspnea and hypoxemia are more prevalent in LTxR and SOTr when compared with the general population and the case fatality ratio appears to be significantly higher in LTxR when compared with other SOTr or the general population (32), although it will likely improve as our knowledge in the management of COVID-19 increases. In many of the reports drugs no longer considered effective (i.e., hydroxychloroquine) were used, while others with potential benefit (i.e., remdesivir) were not available.

There is very scant information regarding changes in spirometry in LTxR infected with SARS-CoV-2. Our experience and anecdotal reports suggest it remains stable in mild cases, even with radiological abnormalities $(24,28)$. Most institutions avoid aerosolizing procedures including spirometry in suspected or proven COVID-19 to prevent exposure to the house staff making it difficult to determine the impact of COVID-19 on pulmonary function tests. Our Lung Transplant Center is following patients' home spirometry to determine clinical progress post COVID-19 infection and/or exposure. In our experience, more severe cases usually show significant decline in spirometry. 
Table 1 Clinical data most commonly reported in Lung transplant recipients compared with the general population and other solid organ transplants with SARS-CoV-2 infection. " $\mathrm{n}=$ " indicates number of patients in whom data was reported

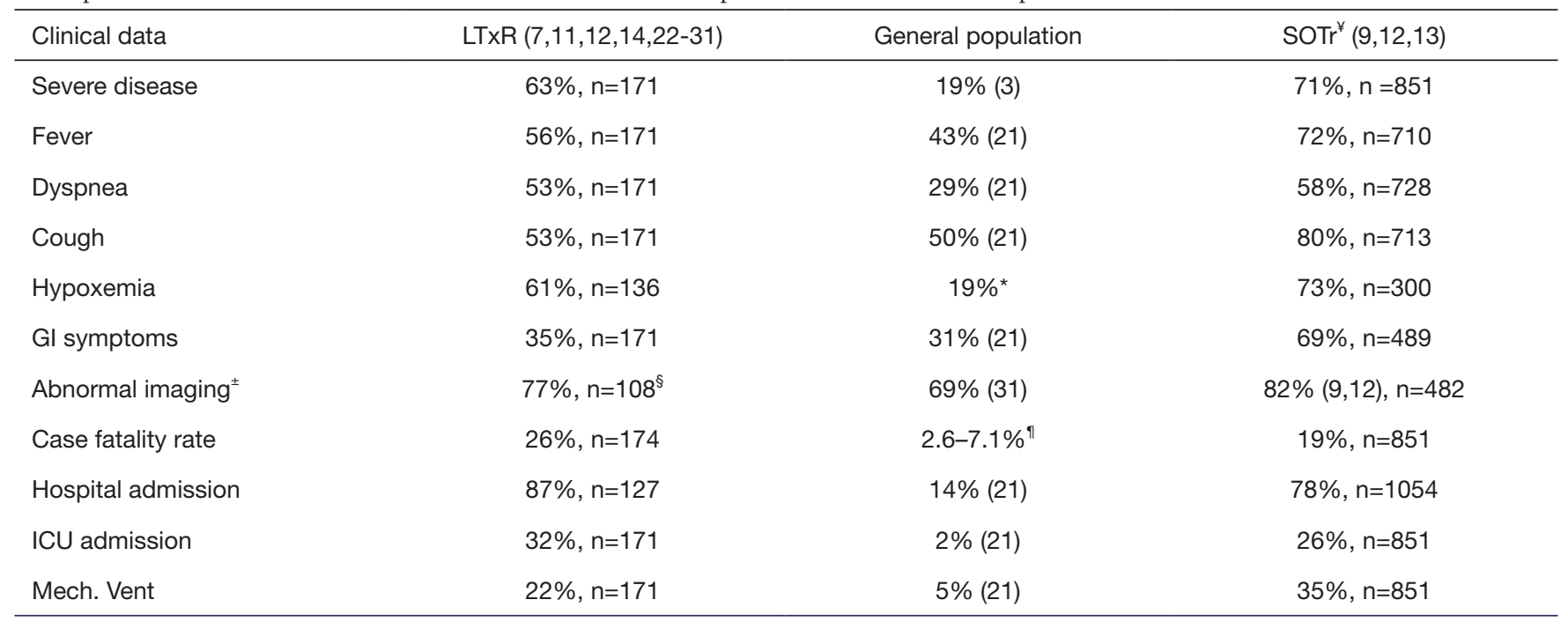

* , includes lung transplant patients: 17 from Pereira (9), and 30 from Kates (12) studies. *, exact incidence is unclear, $19 \%$ estimated based on percentage with moderate to severe cases described in the literature (3), who are presumably hypoxic. ${ }^{ \pm}$, based on data on symptomatic patients at the time they first seek medical attention. ${ }^{\S}$, imaging description specifically reported in $83 / 136$ patients. Mild cases may not have had imaging performed or studies were normal. ", lowest (United States) and highest in Western Europe (Italy) case fatality rate according to Johns Hopkins Coronavirus Resource Center (32). LTxR, lung transplant recipients; SOTr, solid organ transplants recipients; GI, gastrointestinal; ICU, intensive care unit; Mech. Vent, mechanical ventilation.

\section{Diagnosis of COVID-19 disease in lung transplant recipients}

The diagnosis of COVID-19 in LTxR is made in a similar fashion as in the general population. At our institution, we follow the Infectious Diseases Society of America (IDSA) guidelines (33) that recommends SARS-CoV-2 nucleic acid amplification test (NAAT), also known as the reversetranscription polymerase chain reaction (RT-PCR), in symptomatic individuals in the community suspected of having COVID-19, even when the clinical suspicion for COVID-19 is low. Sources for screening specimen include nasopharyngeal (preferred source at our institution), mid turbinate, nasal swabs, oropharyngeal swabs and saliva.

In addition, we also perform NAAT testing under the following circumstances:

(I) All hospitalized patients regardless of symptoms. The IDSA guidelines (33) recommends testing all immunocompromised asymptomatic individuals who are being admitted to the hospital regardless of exposure to COVID-19.

(II) Before any surgical procedure or aerosolgenerating procedure unless there is a negative test within the previous 48 hours.
(III) Patients with a known or suspected contact with a confirmed case of COVID-19.

In LTxR the differential diagnosis of COVID-19 pneumonia include acute allograft rejection, aspiration pneumonia, and acute lung injury from a variety of exposures, in addition to potential opportunistic infections common to any immunosuppressed patient. Chest imaging, including computed tomography of the chest (CTC), is nonspecific (34) and can mimic that of COVID-19 pneumonia. The potential coexistence of other conditions with COVID-19 pneumonia at any time during its course must be kept in mind. The conventional approach of diagnostic bronchoscopy with bronchoalveolar lavage (BAL) and transbronchial biopsies poses risk of exposure to the health care providers and therefore needs to be assessed on a case by case basis. A positive test establishes the diagnosis, but a negative test result should not rule out SARS-CoV-2 infection when there is clinical suspicion given the high incidence of false negative tests. Repeat testing as well as complete isolation is warranted until a diagnosis is established.

Table 2 outlines the testing guidelines by International Society of Heart and Lung Transplant (ISHLT).

At our institution, a nasopharyngeal swab testing for a comprehensive respiratory virus panel is also performed. 
Table 2 Comparison of ISHLT guidelines (35) and Mayo Clinic Florida approach for COVID-19 testing

\begin{tabular}{|c|c|c|}
\hline Situation & ISHLT recommendation (35) & Our approach \\
\hline $\begin{array}{l}\text { Asymptomatic patient } \\
\text { without known contact with } \\
\text { confirmed case of COVID-19 }\end{array}$ & $\begin{array}{l}\text { RT-PCR testing before undergoing any } \\
\text { invasive procedure and prior to } \\
\text { transplantation }\end{array}$ & All patients admitted to the hospital \\
\hline \multirow{3}{*}{$\begin{array}{l}\text { Asymptomatic patient with } \\
\text { contact with confirmed case } \\
\text { of COVID-19 }\end{array}$} & Home quarantine for 2 weeks & Home quarantine for 2 weeks \\
\hline & $\begin{array}{l}\text { Unless mandated by local guidelines, testing } \\
\text { only if symptoms develop }\end{array}$ & "Drive-through" RT-PCR testing \\
\hline & Close monitoring for symptoms & $\begin{array}{l}\text { Close monitoring for symptoms, changes on } \mathrm{SpO}_{2} \text { or } \\
\text { home spirometry }\end{array}$ \\
\hline \multirow{2}{*}{$\begin{array}{l}\text { Patients with symptoms } \\
\text { suspicious for COVID-19 }\end{array}$} & RT-PCR testing according to local guidelines & Mild symptoms: "drive-through" RT-PCR testing \\
\hline & $\begin{array}{l}\text { For patients with negative test consider chest } \\
\text { CT scan }\end{array}$ & $\begin{array}{l}\text { Severe symptoms: evaluation at emergency room with } \\
\text { RT-PCR and extended viral testing }\end{array}$ \\
\hline
\end{tabular}

RT-PCR, reverse-transcription polymerase chain reaction; ISHLT, International Society of Heart and Lung Transplant.
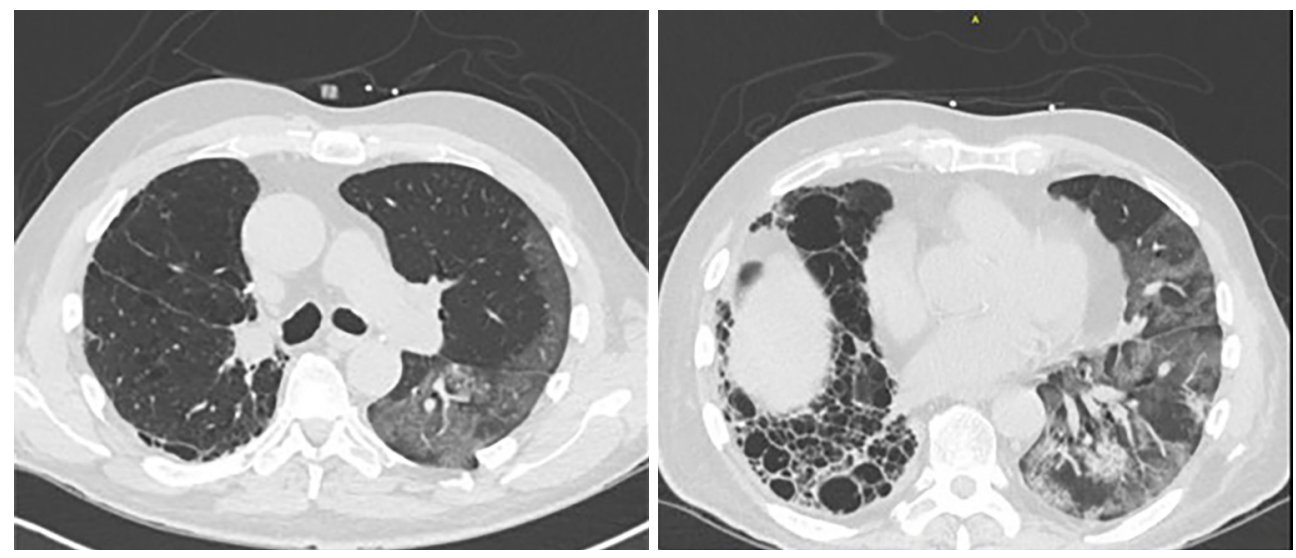

Figure $1 \mathrm{CT}$ scan of the chest of a patient with left lung transplant due to pulmonary fibrosis with ground glass infiltrates only in the allograft.

In patients with two negative tests, or one negative test and worsening clinical status, a diagnostic bronchoscopy is performed to rule out other possible etiologies and to repeat the RT-PCR test on the BAL samples. Although an initial study (36) suggested BAL samples had a much higher sensitivity than nasal swabs, a well-designed study (37) reported an excellent correlation between negative swab tests and BAL samples, and, just as important, an alternative etiologic agent was found in 22 patients.

The most common findings on both chest-X-ray $(\mathrm{CxR})$ and CTC are consolidation and ground-glass opacities, with bilateral, peripheral, and lower lung zone distributions (38-40). Patients with single lung transplantation may show these findings only in the allograft (see Figure 1). As shown in Figure 2, sometimes these radiologic changes persist even after the patient has shown a complete recovery. In a patient with a positive RT-PCR test, we discourage the use of CTC unless there are reasons to believe it will change the management of the patient, like in cases of worsening respiratory status when an alternative cause (i.e., nosocomial infection, pulmonary embolism) is strongly suspected and less cumbersome or invasive testing are non-diagnostic. Because of its lack of specificity imaging studies are of limited benefit in the diagnosis of COVID-19.

We follow the Fleischner Society consensus statement (41) regarding the use of imaging in patients with suspected or 

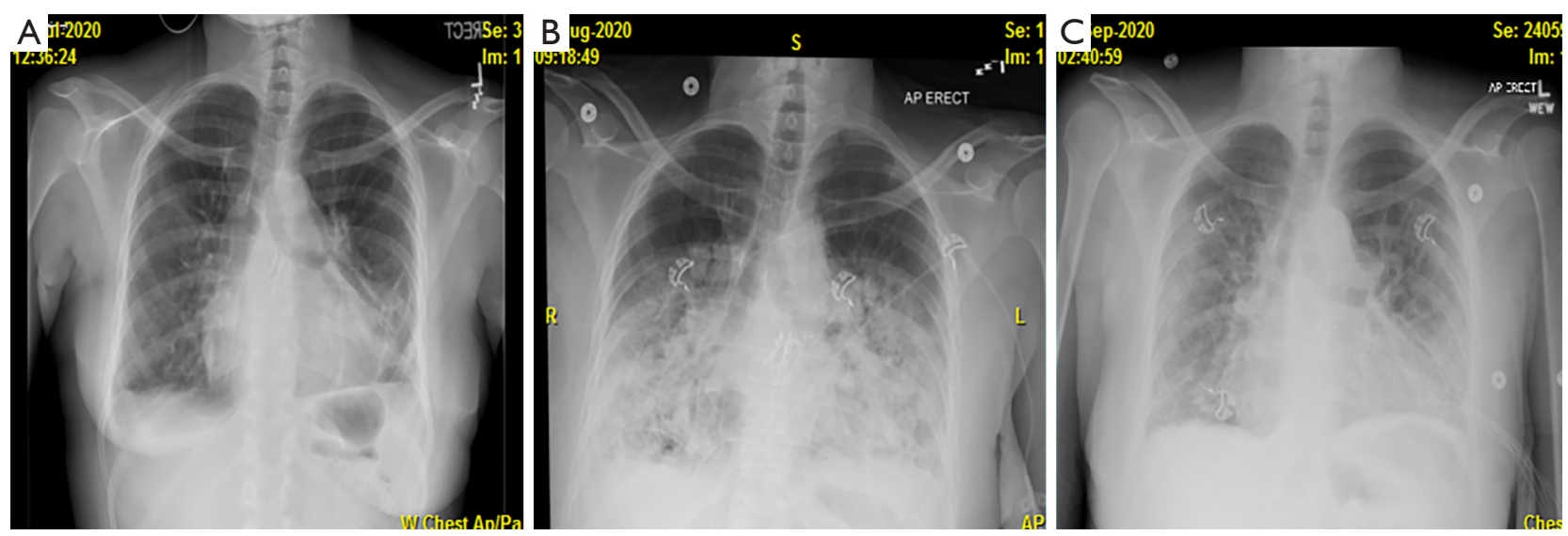

Figure 2 Typical chest-X-ray of a double lung transplant recipient with SARS-CoV-2 pneumonia and hypoxemic respiratory failure. (A) Baseline, (B) during infection, (C) five weeks post infection. The patient was managed with HFNC and iNO. Although the patient no longer requires oxygen therapy, chest-X-ray shows persistent infiltrates. HFNC, high flow nasal cannula; iNO, inhaled nitric oxide.

proven COVID-19:

(I) It is not indicated in patients with suspected COVID-19 and mild clinical features unless they are at risk for disease progression, which is clearly the case in any LTxR.

(II) It is indicated in a patient with COVID-19 and worsening respiratory status.

(III) When resources are scarce, imaging is indicated for medical triage of patients with suspected COVID-19 who present with moderate-severe clinical features and a high pretest probability of disease.

\section{Treatment}

\section{Outpatient treatment}

Any LTxR who develops symptoms suggestive of COVID 19 , has declining home spirometry, or oxygen saturation $\left(\mathrm{SpO}_{2}\right)$ measured by a pulse oximeter $\leq 94 \%$, should be evaluated. We recommend outpatient observation if the patient presents with:

(I) Absent or minimal dyspnea, severe cough, wheezing or pleuritic chest pain.

(II) Oxygen saturation is $\geq 94 \%$, including during normal activities.

(III) Stable expiratory flows by home spirometry.

(IV) Absence of symptoms like nausea and vomiting that could jeopardize the ingestion or absorption of their immunosuppressive medications.

(V) No symptoms consistent with severe disease like hypotension, lethargy, confusion, persistent fever $>38.0^{\circ} \mathrm{C}$, etc.

In the ambulatory setting our protocol includes:

(I) Patient instructions to call for any changes in the parameters described above. Patients are closely followed with phone calls and/or telemedicine visits two to three times a week or as needed. Home spirometry, $\mathrm{SpO}_{2}$ and temperature, are monitored twice a day or as needed.

(II) We recommend acetaminophen for common symptoms like fever, myalgias and headaches.

(III) The role of COVID-19 specific therapy has not been established in mild cases.

(i) We continue azithromycin which is used by most of our patients as part of our posttransplant protocol.

(ii) We do not change our immunosuppression regimen except for increase in prednisone dose from the usual 10 to $20 \mathrm{mg}$ daily. We do not routinely use dexamethasone.

(iii) Anticoagulation is only considered in patients with high risk for venous thromboembolism (VTE).

(IV) We recommend incentive spirometry several times a day, although its utility in patients with COVID-19 has not been established.

(V) Persistent cough is treated with dextromethorphan or benzonatate. Low dose opiates like hydrocodone can be very helpful in well selected patients.

(VI) General counseling and reassurance is vital in symptomatic but otherwise stable patients, given 


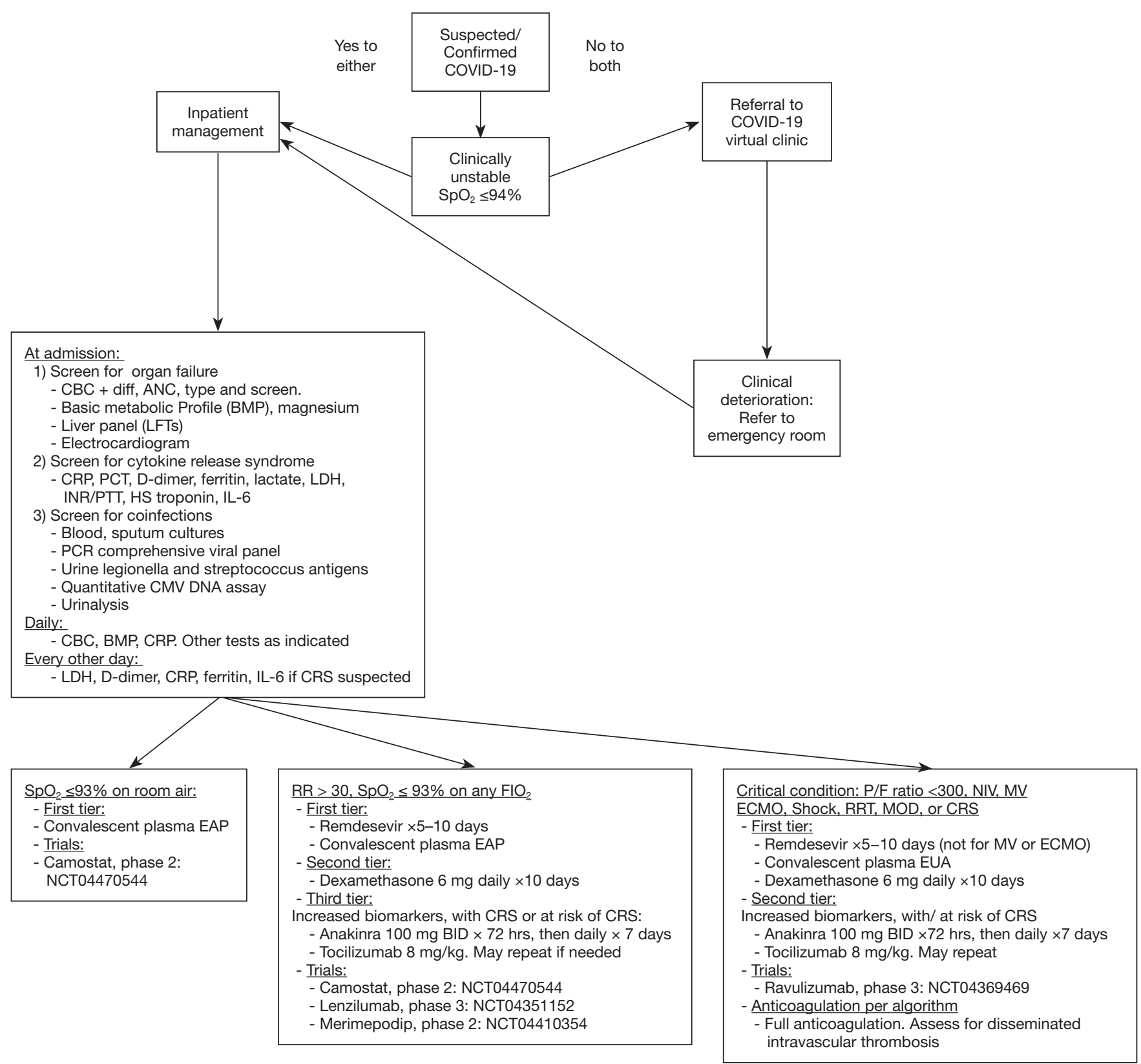

Figure 3 Mayo Clinic Florida protocol for management of COVID-19 patients (42). AB, antibody; ANC, absolute neutrophil count; BMP, basic metabolic panel; CBC, complete blood count; CMV, cytomegalovirus; CRP, C-reactive protein; CRS, cytokine release syndrome; Diff, differential; EUA, emergency use authorization; LDH, lactate dehydrogenase; PCT, procalcitonin; EAP, Expanded Access Program; ECMO, extracorporeal membrane oxygenation.

the degree of anxiety associated with COVID-19.

\section{Management of hospitalized patients}

Patients who do not meet criteria for ambulatory management are admitted to the hospital in a COVID-19 designated area under the care of a multidisciplinary COVID team. The management of hospitalized LTxR very similar to the general population but some issues are unique to LTxR and will be reviewed here. 


\section{General management}

As illustrated in Figure 3, hospitalized patients with SARS$\mathrm{CoV}-2$ infection are closely monitored both clinically, but also with testing aimed at early detection of (I) organ dysfunction, (II) impending CRS, or (III) the presence of coinfections.

Coinfections must be ruled out, both at the time of diagnosis or if there is a change in the clinical status. We usually start empiric antibiotics with the intention to discontinue them as soon as considered safe. In a metaanalysis (42), the prevalence of co-infections in COVID-19 patients was estimated to be around $14 \%$, but this number has been questioned (43) and is probably higher. Limited data suggests LTxR may have a much higher risk of coinfections. In our review of $136 \mathrm{LTxR}$ patients diagnosed with COVID-19 (7,11,14,22-30), the presence or absence of superinfection was documented in 115 patients, and it was diagnosed in 30 patients (26\%). More data is needed to confirm the incidence of superinfections in LTxR.

Clinical deterioration in LTxR poses a major challenge to treating physicians who not only must consider the usual suspects like worsening ARDS, CRS, superinfection, venous thromboembolic disease, cardiac dysfunction and fluid overload, but also acute allograft rejection as well as opportunistic infections like CMV and other viral, fungal, and non-tuberculous mycobacteria infections.

Our approach to a patient with clinical deterioration is aimed to obtain a quick diagnosis with the minimal exposure to the staff.

(I) The biomarkers trend can be very useful. A normal or significant decrease of CRP or IL-6 levels strongly suggests the absence of CRS, while a normal or downtrend on procalcitonin levels indicates that a bacterial infection is much less likely. D-dimer levels trend can also be useful as discussed in the anticoagulation section below.

(II) CTC is helpful to rule out pulmonary embolism or when it presents atypical findings for COVID-19 pneumonia like cavities or pleural effusion. The presence of ground glass infiltrates is nonspecific and requires further investigation.

(III) Doppler ultrasound can be performed at the bedside, minimizing exposure to the personnel, to rule out deep venous thrombosis, assessment of cardiac function and intra vascular volume status.

(IV) If an etiology cannot be determined with the above testing a bronchoscopy with BAL is a reasonable strategy. If negative for infection, the patient can be treated empirically with high dose glucocorticoids (GCC). The specific management of immunosuppression, anticoagulation, pharmacotherapy and respiratory failure are discussed below.

\section{Management of immunosuppression}

Calcineurin inhibitors (CNIs) and mammalian target of rapamycin inhibitors (mTOR) are metabolized by cytochrome P450 (CYP) 3A, with variable bioavailability (44). Mycophenolate mofetil (MMF), a T and $\mathrm{B}$ cell proliferation inhibitor, is metabolized by the enzyme glucuronosyltransferase (45) and is subject to entero-hepatic recirculation, leading to concerns for drugs that affect this process.

Any hyper inflammatory state can lead to phenoconversion of a fast metabolizer into a slow one, which may influence the metabolism of the immunosuppressive drugs, making close monitoring of their levels imperative in LTxR.

The goal of immunosuppression strategy in LTxR is to reach a balance between excessive immunosuppression (which makes patients vulnerable to viral infections) and suboptimal immunosuppression (which may help with viral clearance but could lead to allograft rejection) (46). Furthermore, given the evidence that the immune dysregulation produces many of the devastating effects from SARS-CoV-2 infection (47-49), there is speculation that some degree of immunosuppression may be beneficial to prevent or treat the hyper inflammatory phase of the disease (50), although the evidence in support of this theory is based mostly on anecdotal reports $(26,51,52)$. Some immunosuppressants, such as antimetabolites or lymphocyte-depleting antibodies, can cause lymphopenia, which has been associated with severe SARS-CoV-2 infection, ARDS, ICU admissions and mortality (53). In addition, mTOR inhibitors have been associated to the development of interstitial pneumonitis (54) and most centers will discontinue both of these drugs.

The lack of consensus regarding immunosuppressive therapy was demonstrated in a survey regarding immunosuppression strategies in a hypothetical lung or heart transplant recipient with COVID-19 infection and hypoxemia (at least moderate-severe disease) performed during an ISHLT webinar (55), shown on Table 3.

The official ISHLT guidance (35), is to "consider" holding MMF, mTOR inhibitors or azathioprine in patients with moderate to severe illness.

At our institution, we maintain baseline immunosuppression regimen in patients with mild disease. 


\begin{tabular}{lc}
$\begin{array}{l}\text { Table } 3 \text { ISHLT survey (55) regarding immunosuppression strategies in heart or lung transplant patients with COVID-19 and hypoxemia (n=465 } \\
\text { responders) }\end{array}$ & Percentage \\
\hline Immunosuppression adjustment & $25 \%$ \\
\hline Discontinue MMF only & $22 \%$ \\
No changes in immunosuppression & $18 \%$ \\
Discontinue MMF and reduce tacrolimus & $19 \%$ \\
Reduce MMF and continue tacrolimus & $11 \%$ \\
Reduce MMF and tacrolimus & $4 \%$ \\
Discontinue all immunosuppression. & 4
\end{tabular}

ISHLT, International Society of Heart and Lung Transplant; MMF, mycophenolate mofetil.

We decrease or hold antimetabolites as well as mTOR inhibitors for moderate or severe disease while keeping CNIs at the baseline dose, especially considering its possible effect as an inhibitor of interleukins 1 and 6 pathways, both implicated in the dysregulated immunologic response observed in severe COVID-19.

GCC are frequently used at variable doses, especially since the original report of the benefits of dexamethasone in patients with hypoxemia and severe disease (56). A retrospective study (57) found corticosteroid use in mild cases admitted to a general hospital ward and with $\mathrm{PaO}_{2} /$ $\mathrm{FiO}_{2}$ ratio $<300$ or a $\mathrm{SpO}_{2} / \mathrm{FiO}_{2}$ ratio $<440$ was associated with a significantly lower risk of ICU transfer, intubation or death. In another study the administration of GCC within the first 48 hours of hospitalization was associated with a significant reduction in mortality and mechanical ventilation in patients with CRP levels $\geq 20 \mathrm{mg} / \mathrm{dL}$ (58), but for those with CRP levels $\leq 10 \mathrm{mg} / \mathrm{dL}$ an opposite effect was observed. A meta-analysis (59) of 7 randomized trials including 1,703 critically ill patients concluded that the administration of systemic corticosteroids was associated with a lower 28-day all-cause mortality. A regimen we have used with apparent success is similar to the one reported by Tomazini et al. (60), who reported a significant increase in days alive and free from mechanical ventilation at day 28 with a regimen of $\mathrm{IV}$ dexamethasone administered at a dose of $20 \mathrm{mg}$ IV for five days, followed by $10 \mathrm{mg}$ for five more days or until discharge from ICU.

In the absence of specific guidelines, the administration of GCC is individualized. In a patient with low probability of co-infection, with signs of significant inflammatory state, and/or clinically worsening, we use methylprednisolone in doses up to $10 \mathrm{mg} / \mathrm{kg}$ once a day for $1-3$ days followed by a slow tapper, whereas, in a patient with milder disease we use lower doses of methylprednisolone or prednisone equivalent. Close follow up of clinical status with biomarker assessment on a daily basis dictates following doses and tapering protocols.

\section{Pharmacologic treatment}

Multiple drugs have been used in the treatment of COVID-19 and they are summarized in Table 4.

\section{Antiviral treatment}

The Food and Drug Administration (FDA) have approved remdesivir for treatment of hospitalized subjects with COVID-19 (62), based on several studies (63-65) that suggested potential benefit in mortality, and clinical improvement, although these reports had significant limitations (66). A third study from China (67) showed greater clinical improvement at 28 days but was underpowered to detect a mortality benefit. Although the WHO Solidarity trial (68) which included 2,743 hospitalized patients, showed no mortality benefit, the largest double-blind RCT (69) reported shorter time to recovery and less severe respiratory complications in the treatment group when compared with placebo. On October 22, 2020 the FDA approved the use of remdesivir for the treatment of COVID-19 (62). To date there are no reports of clinically significant interactions between remdesivir and immunosuppressive regimes used for LTxR.

We recommend against the use of lopinavir/ritonavir (L/R) not only because of its inhibiting effects on CYP3A4, which could lead to a significant increase in the CNI serum levels (70-73), but also because of its lack of proven efficacy in the largest and only randomized trial published to date (74), as well as the WHO solidarity trial (68). The IDSA (33) do not recommend its use and NIH (61) recommend using $\mathrm{L} / \mathrm{R}$ only in the context of a clinical trial. 
Table 4 Treatment recommendations for moderate-severe COVID-19 infections

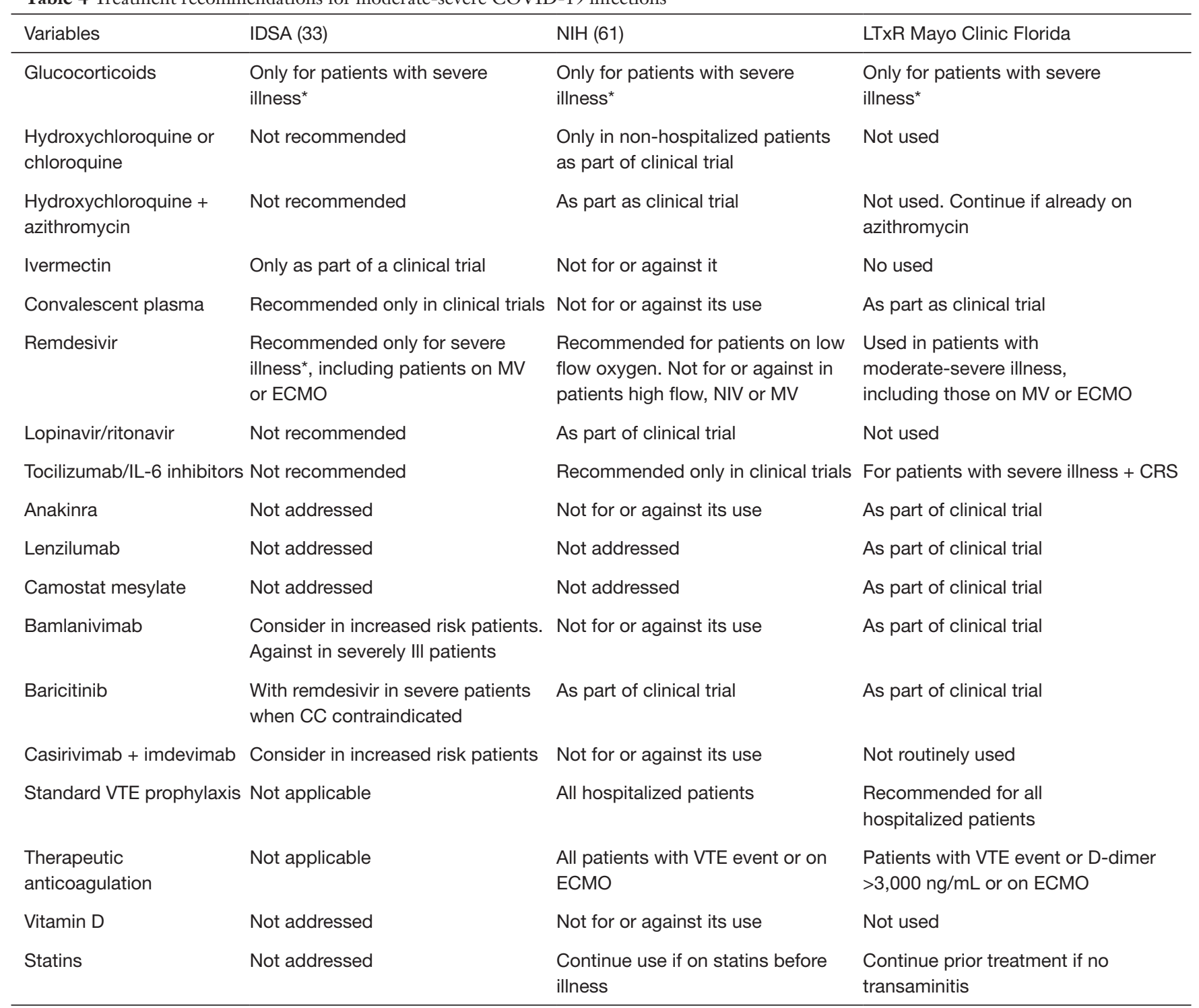

*, defined as patients with $\mathrm{SpO}_{2} \leq 94 \%$ on room air, requiring supplemental oxygen, mechanical ventilation or ECMO. CC, corticosteroids; IDSA, Infectious Diseases Society of America; IL-6, interleukin-6; MV, mechanical ventilation; NIH, National Institutes of Health; NIV, non-invasive ventilation; VTE, venous thromboembolism; ECMO, extracorporeal membrane oxygenation; CRS, cytokine release syndrome.

The same concerns have been raised about other drugs with potential antiviral effects like hydroxychloroquine, azithromycin or ivermectin. If $\mathrm{L} / \mathrm{R}$ is used, tacrolimus dosages as low as $0.5-1 \mathrm{mg}$ once weekly, and $25 \mathrm{mg}$ every 1-2 days for cyclosporine have been recommended, with close monitoring of serum levels (75).

\section{Immune-based therapy}

The use of agents to prevent or ameliorate the CRS characteristic of severe SARS-CoV-2 infection has been a therapeutic target since the beginning of the pandemic. Corticosteroids belong to this category and have been discussed above. Other immunomodulatory agents that have been studied for COVID-19 include interleukin (IL) inhibitors (IL-1 and -6), kinase inhibitors, interferons, Janus kinase (JK) inhibitors, monoclonal antibodies and human blood derived products donated by patients that recovered from SARS-CoV-2 infection, including convalescent plasma transfusion (CPT), immunoglobulin products, mesenchymal 
Table 5 ISHLT survey (55) regarding immunomodulatory therapy in lung transplant patients with COVID-19 ( $\mathrm{n}=544$ responders)

\begin{tabular}{lc}
\hline & Percentage \\
\hline At presentation & $5 \%$ \\
With respiratory deterioration prior to intubation & $34 \%$ \\
After intubation & $11 \%$ \\
Based on inflammatory markers & $40 \%$ \\
Would not use them & $10 \%$ \\
\hline
\end{tabular}

ISHLT, International Society of Heart and Lung Transplant.

stem cells and neutralizing monoclonal antibodies directed against the virus.

None of these agents have proven conclusively to be effective in the treatment of COVID-19 and they have been used only sporadically, if at all, in LTxR. Table 5 describes physician's preferences regarding the use of immunomodulatory therapy, according to the ISHLT survey mentioned above (55).

Tocilizumab (TCZ), an IL-6 blocker, is the most used agent in SOTr. In three of the largest trials of COVID-19 $(9,76,77)$, with a total of 92 kidney transplant recipients with SARS-CoV-2 induced ARDS were treated with TCZ, among other drugs, with a mortality between $30 \%$ to $40 \%$, probably worse than in two reports in severely ill but immunocompetent patients from Italy involving 279 patients with a mortality of $20 \%$ (78) and $25 \%$ (79) respectively. Another study (80) reported a mortality of $18 \%$ of intubated immunocompetent patients compared to $36 \%$ in the control group. This suggests that TCZ, may be less effective in SOTr with SARS-CoV-2 ARDS. A more recent study by Pereira et al. (81) found no mortality benefit in SOTr. On September 25, 2020 the IDSA changed its guidelines (33) and no longer recommends TCZ as treatment for COVID-19 based on a preliminary review of a RCT reported (82) but not peer reviewed at the time, that showed no significant benefit in mortality or clinical status. Two more RCT reported that TCZ was not effective for preventing intubation or death in moderately ill hospitalized patients with COVID-19 (83), and although it reduced the likelihood of progression to the composite outcome of mechanical ventilation and death, it did not improve survival (84), yet a preliminary report of the REMAP-CAP trial showed that TCZ or sarilumab (also an IL-6 inhibitor) reduced mortality and time to ICU discharge (85).

Immunomodulatory therapy may increase the risk of infections, and there are reports of serious infections in SOTr treated with TCZ, including viral (86), bacterial and fungal infections $(80,87,88)$. There are no reports of significant interactions between TCZ and immunosuppressive regimes used for LTxR, but a dramatic TCZ-induced reduction in IL levels can revert the process of phenoconversion, and because of the long life of TCZ it may be prudent to carefully monitor immunosuppression for months (75). We use TCZ in severely ill patients with increased markers suggestive of CRS.

Anakinra is an IL-1 receptor antagonist that has been proposed as a potential therapeutic agent to prevent the CRS associated with COVID-19, and limited data in immunocompetent patients suggests it may improve survival and reduce the need for mechanical ventilation (89-93) and at least as effective as TCZ (94).

There are no clinical trials addressing the use of anakinra in SOTr or LTxR and we found reports of only two patients with severe COVID-19 treated with this drug. One died (24) while the second survived (29). Potential advantages of anakinra include a good safety profile and prior use in solid organ transplant recipients for other indications $(95,96)$. We recommend its use in LTxR only within a clinical trial. The initial experience at Mayo Clinic with lenzilumab (97), a recombinant antibody that targets granulocyte-macrophage colony-stimulating factor (GMCSF), has been promising and clinical trials are underway at our center.

There is no data available regarding the use of other immunomodulators like JK kinase inhibitors (baricitinib) or monoclonal antibodies (bamlanivimab or the combination of casirivimab/imdevimab) in SOTr, although there are promising reports or preliminary data in the general population $(98,99)$ and they have received an emergency use authorization by the FDA (100-102). The ISHLT guidelines (35) report indicates they have low potential for clinical interaction with immunosuppression but cautions about potential subtherapeutic drug levels for calcineurins and mTOR inhibitors. Close monitoring is strongly encouraged with the assistance of the pharmacy service, as well as close surveillance for co-infections.

\section{Anticoagulation}

COVID-19 has been associated with a hypercoagulable state with increased risk of venous (VTE) and arterial thromboembolic events, especially in the critically ill (103-107), and it has been associated to a more severe illness and mortality (108).

Typical laboratory abnormalities include a marked elevation in D-dimer and fibrin degradation products. 


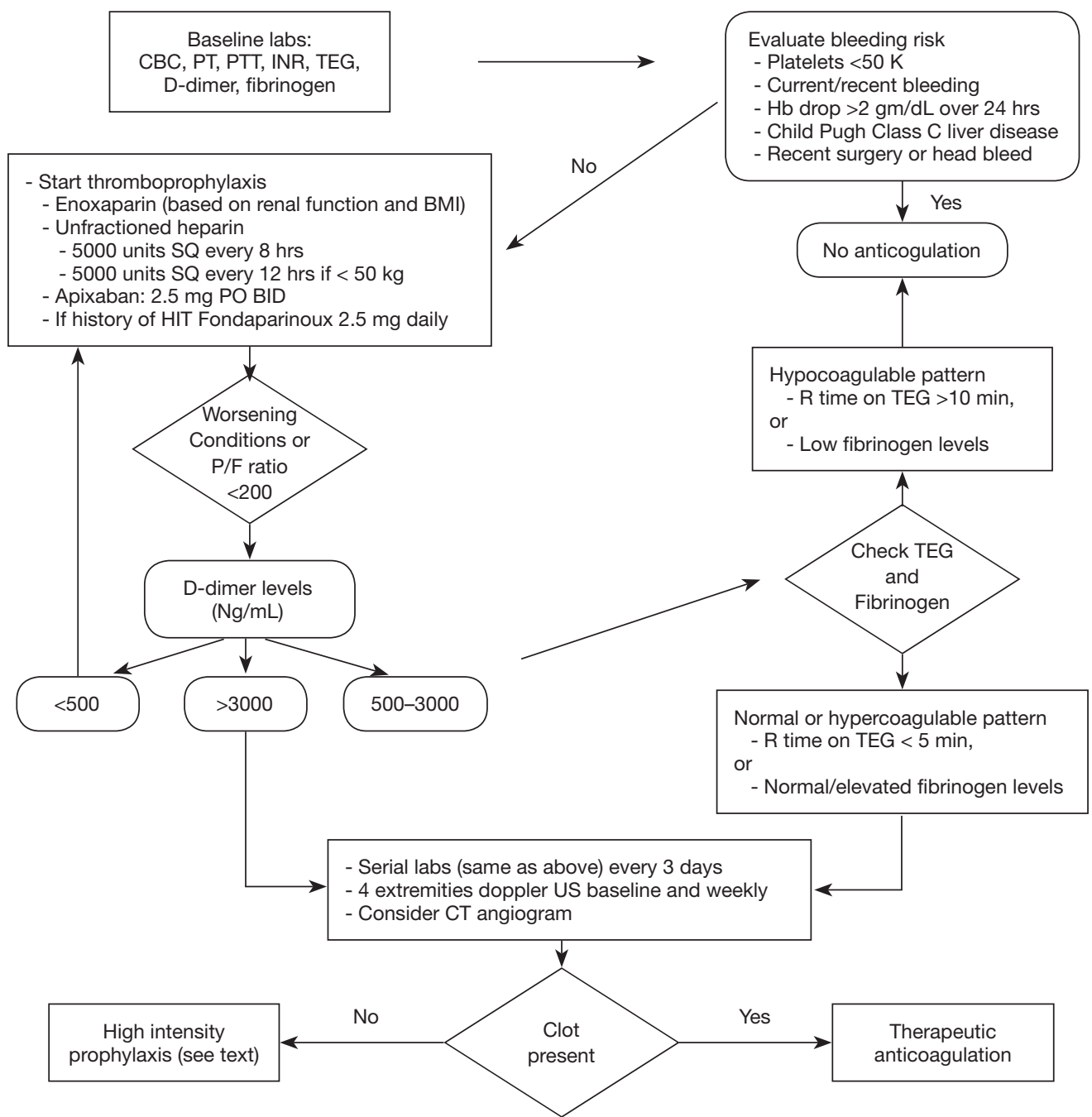

Figure 4 Anticoagulation protocol at Mayo Clinic for hospitalized patients with COVID 19 infection (42). CBC, complete blood count; PT, prothrombin time; PTT, partial thromboplastin time; INR, international normalized ratio; TEG, thromboelastogram; Hb, hemoglobin; HIT, heparin-induced thrombocytopenia.

D-dimer levels $\geq 3 \mu \mathrm{g} / \mathrm{mL}$ have been associated with increased risk of VTE $(103,109)$ and a diminished response to standard prophylaxis (109). The presence of antiphospholipid antibodies (110) and thrombocytopenia (111) have also been reported and associated with increased risk for VTE. Mild alterations in the prothrombin time/international normalized ratio (PT/INR) and activated partial thromboplastin time (aPTT) have been reported $(112,113)$, along with occasional progression to disseminated intravascular coagulation (114).

All hospitalized patients should receive standard prophylactic therapy, and those with proven, or high clinical suspicion of VTE, should receive therapeutic anticoagulation, but it is not clear how to monitor and treat this hypercoagulable state. We favor the approach suggested by the Cleveland Clinic group (115), in which D-dimer, fibrinogen, PT/INR and aPTT are monitored every 48 hours. For those with a D-dimer $\geq 3.0 \mu \mathrm{g} / \mathrm{mL}$ a point-ofcare ultrasound should be performed. For those with proven deep vein thrombosis therapeutic anticoagulation should be administered, while in those with negative ultrasonography high intensity prophylaxis should be considered, usually with heparin, either 7500 units every 8 hours or with a low intensity drip, or enoxaparin, $40 \mathrm{mg}$ every 12 hours.

This approach seems to be supported by a recent study (116) that found that a D-dimer level of $>2,590 \mathrm{ng} / \mathrm{mL}$ 


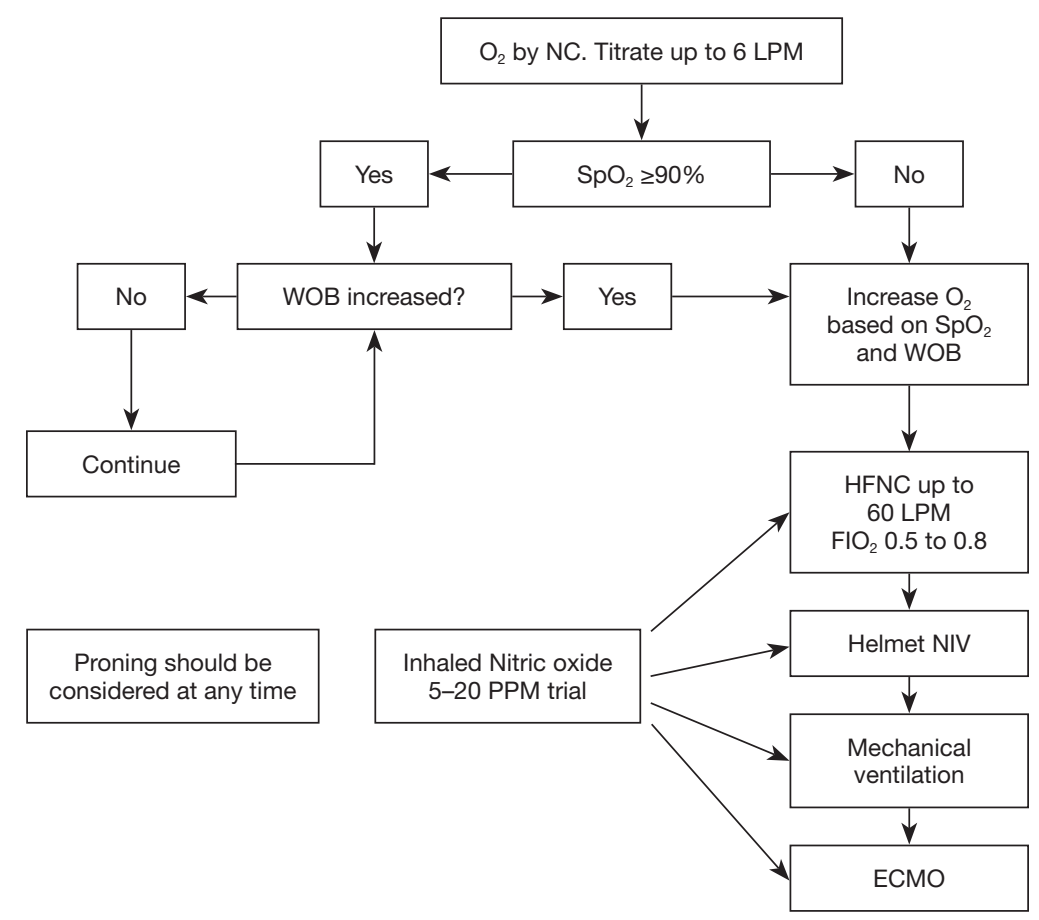

Figure 5 Approach to the management of hypoxic respiratory failure. This is not a rigid protocol and changes should be applied by the bedside clinician as needed (42). Abbreviations, LPM, liters per minute; NC, nasal cannula; HFNC, high flow nasal cannula; NIV, noninvasive ventilation; $\mathrm{SpO}_{2}$, oxygen saturation; WOB, work of breathing; ECMO, extracorporeal membrane oxygenation; PPM, part per million.

was associated with a 17-fold increase risk of VTE and was and an independent predictor pulmonary embolism in patients not receiving anticoagulation. Figure 4 shows our approach to anticoagulation in COVID-19 infected patients.

\section{Convalescent plasma}

CPT obtained from individuals who have recovered from COVID-19 may provide a significant mortality benefit (117), especially if it contains high levels of neutralizing antibody titers, at least $1: 160$, and when administered early during the course of the infection (118$121)$, but evidence is still inadequate (117). Despite its good safety profile $(122,123)$, more studies are needed to corroborate these initial findings. It is not known if the response of LTxR to CPT would be different than the general population, but based on anecdotal reports of poor outcomes for patients with SARS-CoV-2 infection that have received lymphocyte depleting therapy $(124,125)$ and another report of an excellent response in one such a patient, treated with rituximab for lymphoma, after receiving CPT (126) it is tempting to explore if this therapy could be beneficial to our patients who are usually treated with drugs that inhibit B cell activation. In fact, our early experience has shown that many LTxR may not develop anti SARS-CoV-2 antibodies. If this data is confirmed, the administration of CPT, immunoglobulins or monoclonal antibodies may be a useful addition to their treatment.

\section{Management of respiratory failure}

The management of respiratory failure in LTxR is not different than in the general population. A detailed description is beyond the scope of this review, but a few comments about our approach are worth mentioning and are summarized on Figure 5.

\section{In general, our management of respiratory failure is} aimed at three goals

(I) Meet oxygenation requirements. This is not always easily defined, but on clinical grounds it is considered that maintaining a $\mathrm{SpO}_{2} \geq 90 \%$ by pulse oximeter, despite its known limitations, is a reasonable goal.

(II) Maintaining a low level of work of breathing (WOB). Most patients with normal WOB can be managed without invasive mechanical ventilation, even if severe 
hypoxia is present.

(III) Reserve intubation and mechanical ventilation only for patients with refractory hypoxemia and increased WOB. This strategy not only would preserve precious resources, but may avoid potential complications associated with mechanical ventilation.

\section{Non-invasive ventilation (NIV)}

(I) Hypoxic patients who do not respond to oxygen administration by nasal cannula (NC) up to 6 LPM are transitioned into NIV.

(II) NIV is administered by either a high flow nasal cannula (HFNC), from 20-60 LPM and $\mathrm{FIO}_{2}$ from 0.5 to 0.8 , or non-invasive positive pressure ventilation (NIPPV). We favor this approach over early intubation as proposed by some authors. In our experience, these patients can be safely treated in a well monitored unit.

(III) Our preference is HFNC because it is effective and more comfortable, but NIPPV may be more adequate in patients with sleep disorders, hypercapnia, or pulmonary edema. If NIPPV is used, we have had good results with the Helmet system protocol described by the group of the University of Chicago (127), a strategy supported by a report (128) of 157 patients with COVID-19 hypoxemic respiratory failure in which helmet NIPPV was successful in avoiding intubation in $55 \%$ of the patients and it was well tolerated. Conventional CPAP has been reported to avoid intubation in $58 \%$ of patients with COVID-19 and hypoxemic respiratory failure (129) and it is an acceptable option.

Regardless of the NIV implemented, close monitoring is essential to avoid late or emergency intubation. In patients with HFNC, the ROX index (defined as the ratio of $\mathrm{SpO}_{2} / \mathrm{FIO}_{2}$ to respiratory rate) proposed by Roca et al. (130) has been validated as a useful tool to identify those at risk for failure and will likely require mechanical ventilation and has been shown to be useful in patients with COVID-19 (131). Patients on HFNC must wear a mask at all times to decrease exposure by aerosolization (132).

(IV) Despite of lack of evidence of benefit in patients with ARDS (133), and disappointing results in small series in SARS-CoV-2 pneumonia $(134,135)$ we use inhaled nitric oxide (iNO) in patients with severe hypoxia but only if a significant improvement on the gas exchange is observed. In our experience iNO seems to buy enough time in some patients and it may help to prevent intubation while the infection runs its course. One small study reported similar findings (136), but RCT clinical trials are clearly needed.

Mechanical ventilation: this should be the last resort if we fail to achieve the objectives described above

(I) Although the lung protective ventilation strategies for patients with ARDS has been well established (137), an unresolved question in LTxR is if the tidal volume (VT) should be calculated based on the recipient or the donor lung size. In an interesting study, Dezube et al. (138) reported that recipients of undersized grafts received higher VT than recipients of oversized donor grafts, raising concern that former group may be placed at higher risk for ventilator-induced lung injury.

(II) Proper ventilatory management of patients with COVID-19 associated has been controversial since reports emerged suggesting some of these patients may present with a surprisingly normal compliance (139) (phenotype "L", for low elastance), and may benefit from larger VT and lower levels of PEEP than those recommended by the ARDS network $(140,141)$. Although intriguing, until there is more evidence of the benefits of this strategy, we support the conventional ARDS lung protective mechanical ventilation recommended by the ARDS network (137) given available evidence that this ventilatory strategy can be beneficial in patients with ARDS and a relatively good compliance (142), or even without ARDS (143). A report from Janz et al. seems to corroborate these assumptions (144).

(III) The use of high PEEP (145) and proning (146) have been associated with improved survival in patients with ARDS, so until compelling evidence arises to the contrary, our approach will continue to be to follow current evidence-based guidelines.

\section{ECMO}

The use of ECMO in LTxR with COVID-19 induced ARDS patients should follow similar guidelines as for any other patient with ARDS (147). We favor an early referral for ECMO based on the criteria listed on the Table 6 below. These are not exactly the criteria established in the EOLIA trial (148), but we feel this protocol helps to mobilize the resources early with the hope it will prevent irreversible damage to the lungs and other organs, or severe physical deconditioning $(149,150)$. A unique contraindication, in LTxR, is the presence of grade 3 chronic lung allograft dysfunction (CLAD). 
Table 6 Indications and contraindications for the use of ECMO in COVID-19 associated ARDS (147)

\begin{tabular}{ll}
\hline Indications for early referral & Contraindications \\
\hline Rapidly progressive $(6-12 \mathrm{~h})$ respiratory failure & $\begin{array}{l}\text { Irreversible liver/kidney/lung/cardiac failure and } \\
\text { contraindications to transplant }\end{array}$ \\
$\mathrm{SpO}_{2}<90 \%, \mathrm{P} / \mathrm{F}$ ratio $<150, \mathrm{FIO}_{2} \geq 0.7$ & \\
$\mathrm{PCO}_{2}>60, \mathrm{pH}<7.25$ & Terminal malignancy \\
Progressive barotrauma with need of non-protective ventilation settings & Irreversible neurologic injury \\
Early onset of secondary organ failures & Multiorgan failure $>72$ hours \\
Hypercapnia in the setting of established right heart failure & Mechanical ventilation $>7$ days \\
Unstable pulmonary embolism & $\begin{array}{l}\text { Unfavorable vasculature } \\
\text { Evidence of myocarditis }\end{array}$ \\
Rapidly worsening pulmonary compliance & $\begin{array}{l}\text { Patient's wishes, age }>70 \text { years, grade } 3 \text { chronic lung allograft } \\
\text { dysfunction }\end{array}$ \\
\hline
\end{tabular}

ECMO, extracorporeal membrane oxygenation; ARDS, acute respiratory distress syndrome.

\section{Follow up after discharge}

After SARS-CoV-2 infection LTxR are followed in a similar manner as any other patient, according to their clinical condition. The key factor is to determine the duration of isolation. We follow the CDC guidelines (151) that recommend termination of isolation 20 days after symptoms onset and more than 24 hours without fever in severe cases or immunosuppressed patients. The role of RT-PCR testing is unknown, but CDC guidelines allow its use in immunosuppressed patients in consultation with infectious diseases experts. Patients are followed via telemedicine if they are within the isolation period and are seen face to face if outside the isolation period. Baseline immunosuppression is resumed. Emphasis is placed on physical rehabilitation.

\section{Screening of donors and recipients}

The transmission from asymptomatic SARS-CoV-2 carriers has been well documented (152-155) and poses a significant barrier to organ donation given the possibility of transplanting an organ from an infected donor or into an infected recipient, with potential disastrous consequences not only for the recipient but also for the health care personnel (156). Accordingly, all organ procurement and transplantation protocols must be designed to adequately screen both donors and recipients $(157,158)$.

ISHLT guidelines (35) recommend screening all donors and recipients. Information regarding suspicious symptoms as well as potential contacts with symptomatic individuals must be obtained. Another factor to consider is the prevalence of COVID-19 in the donor area. Samples from the respiratory tract should be obtained within three days of procurement and any additional tests performed before the patient was declared a donor, should be reported. In the USA, the United Network for Organ Sharing (UNOS) has modified the DonorNet ${ }^{\circledR}$ data collection program to capture information regarding donor COVID-19 testing.

Whether samples should be taken by BAL or tracheal aspirate versus nasopharyngeal swabs is unknown. We prefer the former but this may not be available at all donor sites. The American Society of Transplantation (AST) recommends one test from both sources (159). Recipients must be informed of the possibility of COVID-19 transmission even from COVID-19 negative donors, and this must be carefully documented. After one of our patients tested positive immediately after transplant, with several subsequent negative samples, excellent postoperative evolution, and no evidence of infection in the donor or other recipients, we decided to obtain a lower respiratory tract sample during procurement to be analyzed at our institution as a control. There are no specific guidelines to screen donors with CTC, but we agree with the Temple University group (160) that this is a necessary tool to evaluate potential lung donors. Any donor with suspicious infiltrates for SARS-CoV-2 $(38,161)$ will be declined at our institution. We do not routinely screen recipients with a CTC unless there are reasons to suspect possible COVID-19. Recipients with new symptoms consistent with SARS-CoV-2 infection are inactivated until a definite conclusion is reached. 
Table 7 ISHLT criteria (35) for reactivation of waitlisted patients after COVID-19 infections

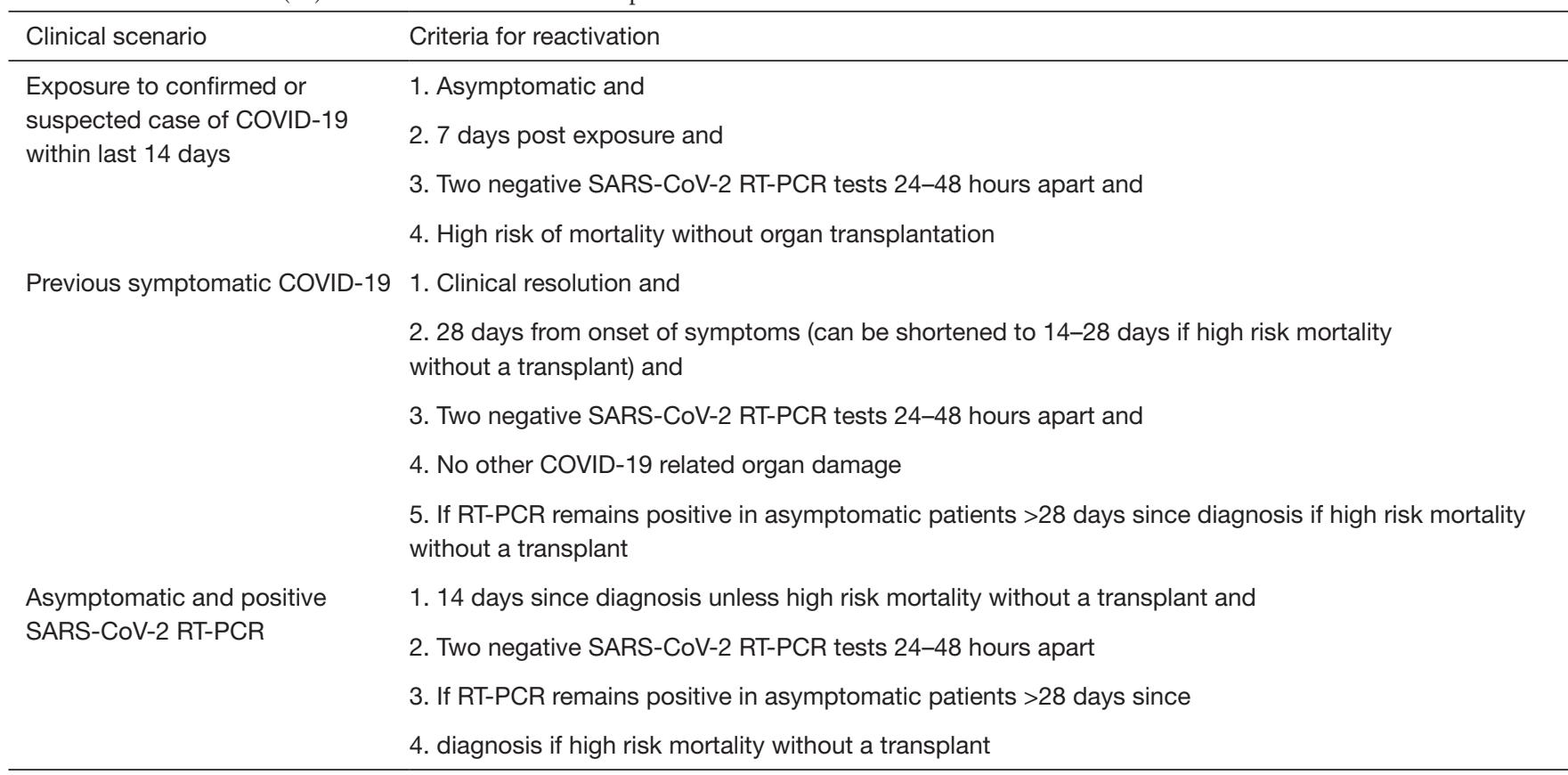

RT-PCR, reverse-transcription polymerase chain reaction; ISHLT, International Society of Heart and Lung Transplant.

There is not enough data regarding the use of donors with prior history of SARS-CoV-2 infection. Our approach is similar to the one proposed by ISHLT (35), which stipulates such donors could be used if it can be established that at least 28 days have elapsed from the onset of symptoms, two negative RT-PCR tests (including a lower respiratory specimen) 24-48 hours apart are negative, and a chest CT scan is normal, in addition to the standard donor criteria $(162,163)$. Information regarding the severity of the COVID-19 donor infection, including a history of mechanical ventilation, shock, and multiorgan failure is also important.

\section{The decision to proceed with transplantation}

This decision must be made by carefully assessing the risk/benefit ratio for the recipient. Several factors must be considered, including severity of underlying pulmonary disease, recent or progressive deterioration, and circumstances that may limit the availability of suitable donors, like extreme heights, blood type, or presence of unacceptable anti HLA antibodies. In areas heavily impacted by the pandemic, consideration should be given to local resources available to manage patients when ICU beds may be scarce.

\section{Reactivation of patients on the waitlist after SARS-CoV-2 infection}

Patients on the waitlist who develop COVID-19 are inactivated. Once recovered, we follow the ISHLT guidelines (35) to consider their reactivation described on Table 7.

\section{Lung transplantation for SARS-CoV-2 chronic respiratory failure recipients}

The number of patients referred for lung transplant due to pulmonary sequela from COVID-19 is expected to rise sharply in the immediate future, but there are no clear guidelines for their evaluation and acceptance as transplant candidates. Table 8 describes the criteria suggested by the Toronto group (164) in reference to a case report of a patient bridged by ECMO and rescued by a lung transplant that we find are applicable for the vast majority of potential post COVID-19 lung injury candidates. Unfortunately, to date we have been able to add to the waitlist very few of these patients because they have developed multiple comorbidities (extreme deconditioning, multiorgan failure) as a result of their COVID-19 disease. Personal communications regarding a very limited number of patients transplanted 
Table 8 Criteria to accept as candidates for lung transplantation patients with chronic respiratory failure after COVID-19 pneumonia [adapted from (164)]

1. At least $4-6$ weeks of recovery time must be allowed after onset of respiratory failure

2. Presence of radiological evidence of irreversible lung injury

3. Patients should be able to participate in physical rehabilitation

4. Patients should meet the established criteria to be candidates for lung transplantation (164)

5. Patients should have a recent negative SARS-CoV-2 PCR result, or prove of absence of viable virus by infectivity assays from lower respiratory tract samples

$\mathrm{PCR}$, polymerase chain reaction.

suggest their outcomes after transplant are rather poor for patients with severe physical deconditioning.

\section{Vaccination for patients in the waitlist or post lung transplantation}

Currently the FDA has issued an EUA for two mRNA based vaccines, the Pfizer-BioNTech (165) and the Moderna (166), but others are expected to be approved soon.

Based on prior experience with other vaccinations, and the safety data accumulated to date, the ISHLT guidelines (35) recommends vaccination against COVID-19 for LTxR and patients awaiting for transplantation who are unlikely to receive an organ donor within 2-3 weeks post vaccination. The guidelines recommend a waiting period of one month posttransplant surgery and 3-6 months after the administration of $\mathrm{T}$ or $\mathrm{B}$-cell depleting agents. Our protocol is 90 days waiting period for both. Whether any of these or future vaccines will trigger an effective immunologic response in LTxR remains to be seen.

\section{Conclusions}

Lung transplant recipients with COVID-19 present in similar ways as the general population, but current evidence suggests they are at higher risk for severe illness. Immunosuppression regimens are frequently unchanged in mild cases, but antimetabolites and mTOR inhibitors are usually held in more severe cases. Glucocorticosteroids are used routinely and frequently in high doses. Anticoagulation and the management of respiratory failure is similar as in the general population. Unless there are concern for interaction with immunosuppressive regimens, LTxR should be included in clinical trials for therapeutic modalities currently under evaluation. Whether COVID-19 is a risk factor for the subsequent development of CLAD is not known at this point, but it will likely be the case, given previously recognized association between CLAD and viral infections. Vaccination for prevention of COVID-19 infection is strongly encouraged given its apparent low risk and potential benefits. Future research should be focused on the management of immunosuppression regimens, the potential effects of current and investigational therapies in the incidence of acute rejection and/or coinfections, the incidence of CLAD after COVID-19 infection, safe strategies to avoid contagion during lung transplantation and the potential effect of COVID-19 infection in the future development of CLAD. Registries of LTxR with COVID-19 are urgently needed to better define treatment strategies in this population.

\section{Acknowledgments}

Funding: None.

\section{Footnote}

Provenance and Peer Review: This article was commissioned by the Guest Editor (George Makdisi) for the series "Lung Transplant: Current Status and Challenges" published in Current Challenges in Thoracic Surgery. The article has undergone external peer review.

Reporting Checklist: The authors have completed the Narrative Review reporting checklist. Available at https:// ccts.amegroups.com/article/view/10.21037/ccts-20-172/rc

Conflicts of Interest: Both authors have completed the ICMJE uniform disclosure form (available at https://ccts.amegroups. com/article/view/10.21037/ccts-20-172/coif). The series "Lung Transplant: Current Status and Challenges" was commissioned by the editorial office without any funding or sponsorship. The authors have no other conflicts of interest 
to declare.

Ethical Statement: The authors are accountable for all aspects of the work in ensuring that questions related to the accuracy or integrity of any part of the work are appropriately investigated and resolved.

Open Access Statement: This is an Open Access article distributed in accordance with the Creative Commons Attribution-NonCommercial-NoDerivs 4.0 International License (CC BY-NC-ND 4.0), which permits the noncommercial replication and distribution of the article with the strict proviso that no changes or edits are made and the original work is properly cited (including links to both the formal publication through the relevant DOI and the license). See: https://creativecommons.org/licenses/by-nc-nd/4.0/.

\section{References}

1. World Health Organization. Director-General's remarks at the media briefing on 2019-nCoV on 11 February 2020. Available online: http://www.who.int/dg/speeches/detail/ who-director-general-s-remarks-at-the-media-briefingon-2019-ncov-on-11-february-2020 (Accessed on August 1st, 2020).

2. Available online: https://www.who.int/dg/speeches/detail/ who-director-general-s-opening-remarks-at-the-mediabriefing-on-covid-19---11-march-2020.

3. Wu Z, McGoogan JM. Characteristics of and Important Lessons From the Coronavirus Disease 2019 (COVID-19) Outbreak in China: Summary of a Report of 72314 Cases From the Chinese Center for Disease Control and Prevention. JAMA 2020;323:1239-42.

4. Zhu N, Zhang D, Wang W, et al. A Novel Coronavirus from Patients with Pneumonia in China, 2019. New Engl J Med 2020;382:727-33.

5. Berlin DA, Gulick RM, Martinez FJ, et al. Severe Covid-19. N Engl J Med 2020;383:2451-60.

6. Scientific evidence for conditions that increase risk of severe illness | COVID-19 | CDC. Available online: https://www.cdc.gov/coronavirus/2019-ncov/need-extraprecautions/evidence-table.html

7. Aversa M, Benvenuto LJ, Anderson MR, et al. COVID-19 in lung transplant recipients: a single center case series from New York City. Am J Transplant 2020;20:3072-80.

8. Fernández-Ruiz M, Andres A, Loinaz C, et al. COVID-19 in solid organ transplant recipients: A single-center case series from Spain. Am J Transplant 2020;20:1849-58
9. Pereira MR, Mohan S, Cohen DJ, et al. COVID-19 in solid organ transplant recipients: initial report from the US epicenter. Am J Transplant 2020;20:1800-8.

10. Akalin. E, Azzi Y, Bartash R, et al. Covid-19 and Kidney Transplantation. New Engl J Med 2020;382:2475-7.

11. Data presented by Erika Lease, MD University of Washington, in the ISHLT Webinar: COVID-19 and Challenges in Advanced Heart and Lung Disease and Cardiothoracic Transplantation. United Network for Organ Sharing. Available online: https://ishltorg/ meetings-education/online-education/ishltv/recordedishltv-webinars/covid-19-and-challenges-in-tx. 2020.

12. Kates OS, Haydel BM, Florman SS, et al. COVID-19 in solid organ transplant: A multi-center cohort study. Clin Infect Dis 2020. doi:101093/cid/ciaa1097.

13. Caillard S, Anglicheau D, Matignon M, et al. Kidney Int. An initial report from the French SOT COVID Registry suggests high mortality due to Covid-19 in recipients of kidney transplants. Kidney Int 2020;98:1549-58.

14. Verleden GM, Godinas L, Lorent N, et al. COVID-19 in lung transplant patients: a case series. Am J Transplant 2020;20:3234-8.

15. Colmenero J, Rodríguez-Perálvarez M, Salcedo M, et al. Epidemiological pattern, incidence, and outcomes of COVID-19 in liver transplant patients. J Hepatol 2021;74:148-55.

16. Columbia University Kidney Transplant Program. Early Description of Coronavirus 2019 Disease in Kidney Transplant Recipients in New York. J Am Soc Nephrol 2020;31:1150-6.

17. Molnar MZ, Bhalla A, Azhar A, et al. Outcomes of critically ill solid organ transplant patients with COVID-19 in the United States. Am J Transplant 2020;20:3061-71.

18. Allyn PR, Duffy EL, Humphries RM, et al. Graft Loss and CLAD-Onset Is Hastened by Viral Pneumonia After Lung Transplantation. Transplantation 2016;100:2424-31.

19. Vandervest KM, Zamora MR. Respiratory viral infections post-lung transplantation. Curr Respir Care Rep 2012;1:162-7.

20. Billings JL, Hertz MI, Savik K, et al. Respiratory viruses and chronic rejection in lung transplant recipients. J Heart Lung Transplant. J Heart Lung Transplant 2002;21:559-66.

21. Stokes EK, Zambrano LD, Anderson KN, et al. Coronavirus Disease 2019 Case Surveillance - United States, January 22-May 30, 2020. MMWR Morb Mortal Wkly Rep 2020;69:759-65.

22. Aigner C, Dittmer U, Kamler M. COVID-19 in a 
lung transplant recipient. J Heart Lung Transplant 2020;39:610-1.

23. Cavagna L, Seminari E, Zanframundo G, et al. Calcineurin Inhibitor-Based Immunosuppression and COVID-19: Results from a Multidisciplinary Cohort of Patients in Northern Italy. Microorganisms 2020;8:977.

24. Morlacchi LC, Rossetti V, Gigli L, et al. COVID-19 in lung transplant recipients: A case series from Milan, Italy. Transpl Infect Dis 2020;22:e13356.

25. Cozzi E, Faccioli E, Marinello S, et al. COVID-19 pneumonia in lung transplant recipients: Report of 2 cases. Am J Transplant 2020;20:2933-7.

26. Desmazes-Dufeu N, Coltey B, Amari L, et al. Discordant courses of Covid-19 in a cohabiting couple of lung transplant recipients. Transpl Infect Dis 2021;23:e13410.

27. Keller BC, Le A, Sobhanie M, et al. Early COVID-19 infection after lung transplantation. Am J Transplant 2020;20:2923-7.

28. Koczulla RA, Sczepanski B, Koteczki A, et al. SARSCov-2 infection in two patients following recent lung transplantation. Am J Transplant 2020;20:2928-32.

29. Myers CN, Scott JH, Criner GJ, et al. COVID-19 in lung transplant recipients. Transpl Infect Dis 2020;22:e13364.

30. Saez-Giménez B, Berastegui C, Barrecheguren M, et al. COVID-19 in lung transplant recipients: A multicenter study. Am J Transplant 2021;21:1816-24.

31. Messika J, Eloy P, Roux A, et al. French Group of Lung Transplantation. COVID-19 in Lung Transplant Recipients. Transplantation 2021;105:177-86.

32. Jonhs Hopkins Coronavirus Resource Center. Available online: https://coronavirusjhuedu/data/mortality. Accessed January 9, 2021.

33. Bhimraj A, Morgan RL, Shumaker AH, et al. Infectious Diseases Society of America Guidelines on the Treatment and Management of Patients with COVID-19. Available online: https://wwwidsocietyorg/practice-guideline/covid19-guideline-treatment-and-management/. Accessed January 10, 2021.

34. Ng YL, Paul N, Patsios D, et al. Imaging of lung transplantation: review. AJR Am J Roentgenol 2009;192:S1-13, quiz S14-9.

35. Aslam S, Danziger-Isakov L, Adler E, et al. Guidance from the International Society of Heart and Lung Transplantation regarding the SARS-CoV-2 pandemic. Available online: https://ishltorg/ishlt/media/documents/ SARS-CoV-2_Guidance-for-Cardiothoracic-Transplantand-VAD-centerspdf. Updated December 4, 2020. Accessed January 10, 2021.
36. Wang W, Xu Y, Gao R, et al. Detection of SARSCoV-2 in Different Types of Clinical Specimens. JAMA 2020;323:1843-4.

37. Geri P, Salton F, Zuccatosta L, et al. Limited role for bronchoalveolar lavage to exclude Covid-19 after negative upper respiratory tract swabs: a multicenter study. Eur Respir J 2020;56:2001733.

38. Pan F, Ye T, Sun P, et al. Time Course of Lung Changes at Chest CT during Recovery from Coronavirus Disease 2019 (COVID-19). Radiology 2020;295:715-21.

39. Zhao W, Zhong Z, Xie X, et al. Relation Between Chest CT Findings and Clinical Conditions of Coronavirus Disease (COVID-19) Pneumonia: A Multicenter Study. AJR Am J Roentgenol 2020;214:1072-7.

40. Wong HYF, Lam HYS, Fong AH. Frequency and Distribution of Chest Radiographic Findings in Patients Positive for COVID-19. Radiology 2020;296:E72-8.

41. Rubin GD, Ryerson CJ, Haramati LB, et al. The Role of Chest Imaging in Patient Management During the COVID-19 Pandemic: A Multinational Consensus Statement From the Fleischner Society. Chest 2020;158:106-16.

42. Lansbury L, Lim B, Baskaran V, et al. Co-infections in people with COVID-19: a systematic review and metaanalysis. J Infect 2020;81:266-75.

43. Bassetti M, Kollef MH, Timsit J. Bacterial and fungal superinfections in critically ill patients with COVID-19. Intensive Care Med 2020;46:2071-4.

44. Elens L, Hesselink DA, van Schaik RH, et al. Pharmacogenetics in kidney transplantation: recent updates and potential clinical applications. Mol Diagn Ther 2012;16:331-45.

45. Benjanuwattra J, Pruksakorn D, Koonrungsesomboon N, et al. Mycophenolic Acid and Its Pharmacokinetic DrugDrug Interactions in Humans: Review of the Evidence and Clinical Implications. J Clin Pharmacol 2020;60:295-311.

46. Zhong Z, Zhang Q, Xia H, et al. Clinical characteristics and immunosuppressant management of coronavirus disease 2019 in solid organ transplant recipients. Am J Transplant 2020;20:1916-21.

47. Ye Q, Wang B, Mao J, et al. The pathogenesis and treatment of the "Cytokine Storm" in COVID-19. J Infect 2020;80:607-13.

48. Henderson LA, Canna SW, Schulert GS, et al. On the alert for Cytokine Storm: Immunopathology in COVID-19. Arthritis Rheumatol 2020;72:1059-63.

49. Cao X. COVID-19: Immunopathology and its implications for therapy. Nat Rev Immunol 2020;20:269-70. 
50. Mehta P, McAuley DF, Brown M, et al. COVID-19: consider cytokine storm syndromes and immunosuppression. Lancet 2020;395:1033-4.

51. Seminari E, Colaneri M, Sambo M, et al. SARS CoV-2 infection in a renal-transplanted patient: A case report Am J Transplant 2020;20:1882-4.

52. Johnson KM, Belfer JJ, Peterson GR, et al. Managing COVID-19 in Renal Transplant Patients: A Review of Recent Literature and Case Supporting Corticosteroidsparing Immunosuppression. Pharmacotherapy 2020;40:517-24.

53. Huang I, Pranata R. Lymphopenia in severe coronavirus disease-2019 (COVID-19): systematic review and metaanalysis. J Intensive Care 2020;8:36.

54. Pham PT, Pham PC, Danovitch GM, et al. Sirolimusassociated pulmonary toxicity. Transplantation 2004;77:1215-20.

55. ISHLT Webinar: COVID-19 and Challenges in Advanced Heart and Lung Disease and Cardiothoracic Transplantation. April 29, 2020. United Network for Organ Sharing. Available online: https://ishltorg/ meetings-education/online-education/ishltv/recordedishltv-webinars/covid-19-and-challenges-in-tx

56. RECOVERY Collaborative Group, Horby P, Lim WS, et al. Dexamethasone in Hospitalized Patients with Covid-19 - Preliminary Report. N Engl J Med 2020. doi:101056/ NEJMoa2021436.

57. Majmundar M, Kansara T, Lenik JM, et al. Efficacy of corticosteroids in non-intensive care unit patients with COVID-19 pneumonia from the New York Metropolitan region. PLoS One 2020;15:e0238827.

58. Keller MJ, Kitsis EA, Arora S, et al. Effect of Systemic Glucocorticoids on Mortality or Mechanical Ventilation in Patients With COVID-19. J Hosp Med 2020;15:489-493.

59. WHO Rapid Evidence Appraisal for COVID-19 Therapies (REACT) Working Group, Sterne JAC, Murthy S, et al. Association Between Administration of Systemic Corticosteroids and Mortality Among Critically Ill Patients With COVID-19: A Meta-analysis. JAMA 2020;324:1330-41.

60. Tomazini BM, Maia IS, Cavalcanti AB, et al. Effect of Dexamethasone on Days Alive and Ventilator-Free in Patients With Moderate or Severe Acute Respiratory Distress Syndrome and COVID-19: The CoDEX Randomized Clinical Trial. JAMA 2020;324:1307-16.

61. COVID-19 Treatment guidelines Panel. Coronavirus Disease (COVID-19) Treatment Guidelines. National Institutes of Health. Available online: https:// covid19treatmentguidelines.nih.gov/. Accessed January 16, 2021.

62. Available online: https://www.fda.gov/news-events/pressannouncements/fda-approves-first-treatment-covid-19

63. Goldman JD, Lye DCB, Hui DS, et al. Remdesivir for 5 or 10 Days in Patients with Severe Covid-19. N Engl J Med 2020;383:1827-37.

64. Beigel JH, Tomashek KM, Dodd LE, et al. Remdesivir for the Treatment of Covid-19 - Preliminary Report. N Engl J Med 2020;383:994.

65. Grein J, Ohmagari N, Shin D, et al. Compassionate Use of Remdesivir for Patients with Severe Covid-19. New Engl J Med 2020;382:2327-36.

66. Doggrell SA. Remdesivir, a remedy or a ripple in severe COVID-19? Expert Opin Investig Drugs 2020;29:1195-8.

67. Wang Y, Zhang D, Du G, et al. Remdesivir in adults with severe COVID-19: a randomised, double-blind, placebocontrolled, multicentre trial. Lancet 2020;395:1569-78.

68. Pan H, Peto R, Abdool Karim Q, et al. Repurposed antiviral drugs for COVID-19; interim WHO SOLIDARITY trial results WHO Solidarity Trial Consortium. medRxiv 2020101520209817.

69. Beigel JH, Tomashek KM, Dodd LE, et al. Remdesivir for the Treatment of Covid-19 - Final Report. N Engl J Med 2020;383:1813-26.

70. Bartiromo M, Borchi B, Botta A, et al. Threatening drug-drug interaction in a kidney transplant patient with coronavirus disease 2019 (COVID-19). Transpl Infect Dis 2020;22:e13286.

71. Xia T, Wang Y. Coronavirus disease 2019 and transplantation: The combination of lopinavir/ritonavir and hydroxychloroquine is responsible for excessive tacrolimus trough level and unfavorable outcome. Am J Transplant 2020;20:2630-1.

72. Jain AB, Venkataramanan R, Eghtesad B, et al. Effect of coadministered lopinavir and ritonavir (Kaletra) on tacrolimus blood concentration in liver transplantation patients. Liver Transpl 2003;9:954-60.

73. Vogel M, Voigt E, Michaelis HC, et al. Management of drug-to-drug interactions between cyclosporine A and the protease-inhibitor lopinavir/ritonavir in liver-transplanted HIV-infected patients. Liver Transpl 2004;10:939-44.

74. Cao B, Wang Y, Wen D, et al. A Trial of LopinavirRitonavir in Adults Hospitalized with Severe Covid-19. New Engl J Med 2020;382:1787-99.

75. Elens L, Langman L, Hesselink D, et al. Pharmacologic Treatment of Transplant Recipients Infected With SARSCoV-2: Considerations Regarding Therapeutic Drug 
Monitoring and Drug-Drug Interactions. Ther Drug Monit 2020;42:360-8.

76. Pérez-Sáez MJ, Blasco M, Redondo-Pachón D, et al. Use of tocilizumab in kidney transplant recipients with COVID-19. Am J Transplant 2020;20:3182-90.

77. Trujillo H, Caravaca-Fontán F, Sevillano Á, et al. Tocilizumab use in Kidney Transplant Patients with Covid-19. Clin Transplant 2020;34:e14072.

78. Toniati P, Piva S, Cattalini M, et al. Tocilizumab for the treatment of severe COVID-19 pneumonia with hyperinflammatory syndrome and acute respiratory failure: A single center study of 100 patients in Brescia, Italy. Autoimmun Rev 2020;19:102568.

79. Guaraldi G, Meschiari M, Cozzi-Lepri A, et al. Tocilizumab in patients with severe COVID-19: a retrospective cohort study. Lancet Rheumatol 2020;2:e474-84.

80. Somers EC, Eschenauer GA, Troost JP, et al. Tocilizumab for treatment of mechanically ventilated patients with COVID-19. Clin Infect Dis 2020. doi: 10.1093/cid/ ciaa954.

81. Pereira MR, Aversa MM, Farr MA, et al. Tocilizumab for severe COVID-19 in solid organ transplant recipients: a matched cohort study. Am J Transplant 2020;20:3198-205.

82. Rosas IO, Bräu N, Waters M, et al. Tocilizumab in Hospitalized Patients with Severe Covid-19 Pneumonia. N Engl J Med 2021. doi: 10.1056/NEJMoa2028700.

83. Stone JH, Frigault MJ, Serling-Boyd NJ, et al. Efficacy of Tocilizumab in Patients Hospitalized with Covid-19. New Engl J Med 2020;383:2333-44.

84. Salama C, Han J, Yau L, et al. Tocilizumab in Patients Hospitalized with Covid-19 Pneumonia. New Engl J Med 2021;384:20-30.

85. Gordon AC, Mouncey PR, Al-Beidh F, et al. Interleukin-6 Receptor Antagonists in Critically Ill Patients with Covid-19 - Preliminary report. medRxiv 2021. doi: 10.1101/2021.01.07.

86. Busani S, Bedini A, Biagioni E, et al. Two fatal cases of acute liver failure due to HSV-1 infection in COVID-19 patients following immunomodulatory therapies. Clin Infect Dis 2021;73:e252-5.

87. Pettit NN, Nguyen CT, Mutlu GM, et al. Late onset infectious complications and safety of tocilizumab in the management of COVID-19. J Med Virol 2021;93:1459-64.

88. Antinori S, Bonazzetti C, Gubertini G, et al. Tocilizumab for cytokine storm syndrome in COVID-19 pneumonia: an increased risk for candidemia? Autoimmun Rev 2020;19:102564.
89. Cavalli G, De Luca G, Campochiaro C, et al. Interleukin-1 blockade with high-dose anakinra in patients with COVID-19, acute respiratory distress syndrome, and hyperinflammation: a retrospective cohort study. Lancet Rheumatol 2020;2:e325-31.

90. Huet T, Beaussier H, Voisin O, et al. Anakinra for severe forms of COVID-19: a cohort study. Lancet Rheumatol 2020;2:e393-e400.

91. Iglesias-Julián E, López-Veloso M, de la Torre Ferrera $\mathrm{N}$, et al. High dose subcutaneous Anakinra to treat acute respiratory distress syndrome secondary to cytokine storm syndrome among severely ill COVID-19 patients. J Autoimmun 2020;115:102537.

92. Borie R, Savale L, Dossier A, et al. Glucocorticoids with low-dose anti-IL1 anakinra rescue in severe nonICU COVID-19 infection: A cohort study. PLoS One 2020;15:e0243961.

93. Bozzi G, Mangioni D, Minoia F, et al. Anakinra combined with methylprednisolone in patients with severe COVID-19 pneumonia and hyperinflammation: An observational cohort study. J Allergy Clin Immunol 2021;147:561-566.e4.

94. Langer-Gould A, Smith JB, Gonzales E, et al. Early identification of COVID-19 cytokine storm and treatment with anakinra or tocilizumab. Int J Infect Dis 2020;99:291-7.

95. Loustau C, Rosine N, Forien M, et al. Effectiveness and safety of anakinra in gout patients with stage 4-5 chronic kidney disease or kidney transplantation: A multicentre, retrospective study. Joint Bone Spine 2018;85:755-60.

96. Mulders-Manders CM, Baas MC, Molenaar FM, et al. Peri- and Postoperative Treatment with the Interleukin-1 Receptor Antagonist Anakinra Is Safe in Patients Undergoing Renal Transplantation: Case Series and Review of the Literature. Front Pharmacol 2017;8:342.

97. Temesgen Z, Assi M, Shweta FNU, et al. GM-CSF Neutralization With Lenzilumab in Severe COVID-19 Pneumonia: A Case-Cohort Study. Mayo Clin Proc 2020;95:2382-94.

98. Kalil AC, Patterson TF, Mehta AK, et al. Baricitinib plus Remdesivir for Hospitalized Adults with Covid-19. N Engl J Med 2021;384:795-807.

99. Weinreich DM, Sivapalasingam S, Norton T, et al. REGN-COV2, a Neutralizing Antibody Cocktail, in Outpatients with Covid-19. N Engl J Med 2021;384:238-51.

100. Fact sheet for health care providers emergency use authorization (EUA) of baricitinib. Available online: 
https://www.fda.gov/media/143823/download

101. Fact sheet for health care providers emergency use authorization (EUA) of bamlanivimab. Available online: https://www.fda.gov/media/143603/download

102. Fact sheet for health care providers emergency use authorization (EUA) of casirivimab and imdevimab. Available online: https://www.fda.gov/media/143892/ download

103. Cui S, Chen S, Li X, et al. Prevalence of venous thromboembolism in patients with severe novel coronavirus pneumonia. J Thromb Haemost 2020;18:1421-4.

104.Klok FA, Kruip MJHA, van der Meer NJM, et al. Incidence of thrombotic complications in critically ill ICU patients with COVID-19. Thromb Res 2020;191:145-7.

105. Panigada M, Bottino N, Tagliabue P, et al. Hypercoagulability of COVID 19 patients in intensive care unit: A report of thromboelastography findings and other parameters of hemostasis. J Thromb Haemost 2020;18:1738-42.

106. Connors JM, Levy JH. COVID-19 and its implications for thrombosis and anticoagulation. Blood 2020;135:2033-40.

107. Bilaloglu S, Aphinyanaphongs Y, Jones S, et al. Thrombosis in Hospitalized Patients With COVID-19 in a New York City Health System. JAMA 2020;324:799-801.

108. Wu C, Chen X, Cai Y. Risk factors associated with acute respiratory distress syndrome and death in patients with coronavirus disease 2019 pneumonia in Wuhan, China. JAMA Intern Med 2020;180:934-43.

109. Maatman TK, Jalali F, Feizpour C, et al. Routine Venous Thromboembolism Prophylaxis May Be Inadequate in the Hypercoagulable State of Severe Coronavirus Disease 2019. Crit Care Med 2020;48:e783-90.

110.Helms J, Tacquard C, Severac F, et al. High risk of thrombosis in patients with severe SARS-CoV-2 infection: a multicenter prospective cohort study. Intensive Care Med 2020;46:1089-98.

111.Lippi G, Plebani M, Henry BM, et al. Thrombocytopenia is associated with severe coronavirus disease 2019 (COVID-19) infections: A meta-analysis. Clin Chim Acta 2020;506:145-8.

112. Yin S, Huang M, Li D, et al. Difference of coagulation features between severe pneumonia induced by SARSCoV2 and non-SARS-CoV2. J Thromb Thrombolysis 2021;51:1107-10.

113. Han H, Yang L, Liu R, et al. Prominent changes in blood coagulation of patients with SARS-CoV-2 infection. Clin Chem Lab Med 2020;58:1116-20.
114. Tang N, Bai H, Chen X, et al. Anticoagulant treatment is associated with decreased mortality in severe coronavirus disease 2019 patients with coagulopathy. J Thromb Haemost 2020;18:1094-9.

115.Mucha SR, Dugar S, McCrae K, et al. Coagulopathy in COVID-19: Manifestations and management. Cleve Clin J Med 2020;87:461-8.

116. Mouhat B, Besutti M, Bouiller K, et al. Elevated D-dimers and lack of anticoagulation predict PE in severe COVID-19 patients. Eur Respir J 2020;56:2001811.

117. Chai KL, Valk SJ, Piechotta V, et al. Convalescent plasma or hyperimmune immunoglobulin for people with COVID-19: a living systematic review. Cochrane Database Syst Rev 2020;10:CD013600.

118. Salazar E, Christensen PA, Graviss EA, et al. Treatment of Coronavirus Disease 2019 Patients with Convalescent Plasma Reveals a Signal of Significantly Decreased Mortality. Am J Pathol 2020;190:2290-303.

119. Joyner MJ, Senefeld JW, Klassen SA. Effect of Convalescent Plasma on Mortality among Hospitalized Patients with COVID-19: Initial Three-Month Experience. Preprint. medRxiv 2020. doi:101101/2020081220169359.

120.Li L, Zhang W, Hu Y, et al. Effect of Convalescent Plasma Therapy on Time to Clinical Improvement in Patients With Severe and Life-threatening COVID-19: A Randomized Clinical Trial. JAMA 2020;324:460-70.

121.Libster R, Pérez Marc G, Wappner D, et al. Early HighTiter Plasma Therapy to Prevent Severe Covid-19 in Older Adults. N Engl J Med 2021;384:610-8.

122.Joyner MJ, Bruno KA, Klassen SA, et al. Safety Update: COVID-19 Convalescent Plasma in 20,000 Hospitalized Patients. Mayo Clin Proc 2020;95:1888-97.

123. Joyner MJ, Wright RS, Fairweather D. Early safety indicators of COVID-19 convalescent plasma in 5000 patients. J Clin Invest 2020;130:4791-7.

124. Guilpain P, Le Bihan C, Foulongne V, et al. Response to: 'Severe COVID-19 associated pneumonia in 3 patients with systemic sclerosis treated with rituximab' by Avouac et al. Ann Rheum Dis 2020. doi: 10.1136/ annrheumdis-2020-217955.

125. Guilpain P, Le Bihan C, Foulongne V, et al. Rituximab for granulomatosis with polyangiitis in the pandemic of covid-19: lessons from a case with severe pneumonia. Ann Rheum Dis 2021;80:e10.

126. Clark E, Guilpain P, Filip IL, et al. Convalescent plasma for persisting COVID-19 following therapeutic lymphocyte depletion: a report of rapid recovery. Br J 
Haematol 2020;190:e154-6.

127.Patel BK, Wolfe KS, Pohlman AS, et al. Effect of Noninvasive Ventilation Delivered by Helmet vs Face Mask on the Rate of Endotracheal Intubation in Patients With Acute Respiratory Distress Syndrome: A Randomized Clinical Trial. JAMA 2016;315:2435-41.

128. Aliberti S, Radovanovic D, Billi F, et al. Helmet CPAP treatment in patients with COVID-19 pneumonia: a multicentre cohort study. Eur Respir J 2020;56:2001935.

129. Nightingale R, Nwosu N, Kutubudin F, et al. Is continuous positive airway pressure (CPAP) a new standard of care for type 1 respiratory failure in COVID-19 patients? A retrospective observational study of a dedicated COVID-19 CPAP service. BMJ Open Respir Res 2020;7:e00639

130. Roca O, Caralt B, Messica J, et al. An Index Combining Respiratory Rate and Oxygenation to Predict Outcome of Nasal High-Flow Therapy. Am J Respir Crit Care Med 2019;199:1368-76.

131. Chandel A, Patolia S, Brown AW, et al. High-flow nasal cannula in COVID-19: Outcomes of application and examination of the ROX index to predict success. Respir Care 2020. doi: 10.4187/respcare.08631.

132. Hui DS, Chow BK, Chu L, et al. Exhaled air dispersion during coughing with and without wearing a surgical or N95 mask. PLoS One 2012;7:e50845.

133. Adhikari NK, Dellinger RP, Lundin S, et al. Inhaled nitric oxide does not reduce mortality in patients with acute respiratory distress syndrome regardless of severity: systematic review and meta-analysis. Crit Care Med 2014;42:404-12.

134. Tavazzi G, Marco P, Mongodi S, et al. Inhaled nitric oxide in patients admitted to intensive care unit with COVID-19 pneumonia. Crit Care 2020;24:508.

135. Ferrari M, Santini A, Protti A, et al. Inhaled nitric oxide in mechanically ventilated patients with COVID-19. J Crit Care 2020;60:159-60.

136.Parikh R, Wilson C, Weinberg J, et al. Inhaled nitric oxide treatment in spontaneously breathing COVID-19 patients. Ther Adv Respir Dis 2020. doi: 10.1177/1753466620933510.

137. Brower RG, Matthay MA, et al. Acute Respiratory Distress Syndrome Network. Ventilation with lower tidal volumes as compared with traditional tidal volumes for acute lung injury and the acute respiratory distress syndrome. New Engl J Med 2000;342:1301-8.

138. Dezube R, Arnaoutakis GJ, Reed RM, et al. The effect of lung-size mismatch on mechanical ventilation tidal volumes after bilateral lung transplantation. Interact

Cardiovasc Thorac Surg 2013;16:275-81.

139. Gattinoni L, Coppola S, Cressoni M, et al. COVID-19 Does Not Lead to a "Typical" Acute Respiratory Distress Syndrome. Am J Respir Crit Care Med 2020;201:1299-300.

140. Gattinoni L, Chiumello D, Caironi P, et al. COVID-19 pneumonia: different respiratory treatments for different phenotypes? Intensive Care Med 2020;46:1099-102.

141. Marini JJ, Gattinoni L. Management of COVID-19 respiratory distress. JAMA 2020;323:2329-30.

142. Hager DN, Krishnan JA, Hayden DL, et al. ARDS Clinical Trials Network. Tidal volume reduction in patients with acute lung injury when plateau pressures are not high. Am J Respir Crit Care Med 2005;172:1241-5.

143. Serpa Neto A, Cardoso SO, Manetta JA, et al. Association between use of lung-protective ventilation with lower tidal volumes and clinical outcomes among patients without acute respiratory distress syndrome: a meta-analysis. JAMA 2012;308:1651-9.

144.Janz DR, Mackey S, Patel N, et al. Critically Ill Adults With Coronavirus Disease 2019 in New Orleans and Care With an Evidence-Based Protocol. Chest 2021;159:196-204.

145. Briel M, Meade M, Mercat A, et al. Higher vs lower positive end-expiratory pressure in patients with acute lung injury and acute respiratory distress syndrome: systematic review and meta-analysis. JAMA 2010;303:865-73.

146. Guérin C, Reignier J, Richard JC, et al. Prone positioning in severe acute respiratory distress syndrome. New Engl J Med 2013;368:2159-68.

147.Rajagopal K, Keller SP, Akkanti B, et al. Advanced Pulmonary and Cardiac Support of COVID-19 Patients: Emerging Recommendations From ASAIO-a Living Working Document. Circ Heart Fail 2020;13:e007175.

148. Combes A, Hajage D, Capellier G, et al. Extracorporeal Membrane Oxygenation for Severe Acute Respiratory Distress Syndrome. New Engl J Med 2018;378:1965-75.

149. Taniguchi H, Ogawa F, Honzawa H, et al. Venovenous extracorporeal membrane oxygenation for severe pneumonia: COVID-19 case in Japan. Acute Med Surg 2020;7:e509.

150.Zhan WQ, Li MD, Xu M, et al. Successful treatment of COVID-19 using extracorporeal membrane oxygenation, a case report. Eur Rev Med Pharmacol Sci 2020;24:3385-9.

151.Available online: https://www.cdc.gov/coronavirus/2019ncov/hcp/duration-isolation.html. Updated October 10, 2020. Accessed January 16, 2021.

152.Kimball A, Hatfield KM, Arons M, et al. Asymptomatic 
and presymptomatic Sars-Cov-2 infections in residents of a long-term skilled nursing facility - King County, Washington. March 2020 MMWR Morb Mortal Wkly Rep 2020;69:377-81.

153. Qian G, Yang N, Ma A, et al. A COVID-19 transmission within a family cluster by presymptomatic infectors in China. Clin Infect Dis 2020;71:861-2.

154.Le TQM, Takemura T, Moi ML, et al. Severe acute respiratory syndrome coronavirus 2 shedding by Travelers, Vietnam, 2020. Emerg Infect Dis 2020;26:1624-6.

155. Rothe C, Schunk M, Sothmann P, et al. Transmission of 2019-nCoV Infection from an Asymptomatic Contact in Germany. New Engl J Med 2020;382:970-1.

156. American Society of Transplant Surgeons. Available online: https://asts.org/advocacy/covid-19-resources/astscovid-19-strike-force/asts-covid-19-strike-force-initialguidance\#.X01250JKjIU. Accessed August 31st, 2020.

157.Galvan NTN, Moreno NF, Garza JE, et al. Donor and transplant candidate selection for solid organ transplantation during the COVID-19 pandemic. Am J Transplant 2020;20:3113-22.

158. Chen CY, Chen SF, Hollander SA. Donor heart selection during the COVID-19 pandemic: A case study. J Heart Lung Transplant 2020;39:497-8.

doi: $10.21037 /$ ccts-20-172

Cite this article as: Alvarez-Aquino FG, Shah S. Lung transplantation: challenges in the COVID-19 era, a narrative review of the literature. Curr Chall Thorac Surg 2021;3:29.
159. American Society of Transplantation. Available online: https://www.myast.org/sites/default/files/Donor\%20 Testing-10.5.20-Final.pdf. Accessed October 11, 2020.

160. Shigemura N, Cordova F, Criner G, et al. Current precautions and future directions in lung transplantation during the COVID-19 pandemic. Transpl Int 2020;33:1453-7.

161.Han R, Huang L, Jiang H, et al. Early Clinical and CT Manifestations of Coronavirus Disease 2019 (COVID-19) Pneumonia. AJR Am J Roentgenol 2020;215:338-43.

162. Orens JB, Boehler A, de Perrot M, et al. A review of lung transplant donor acceptability criteria. J Heart Lung Transplant 2003;22:1183-200.

163. Courtwright A, Cantu E. Evaluation and Management of the Potential Lung Donor. Clin Chest Med 2017;38:751-9.

164. Cypel M, Keshavjee S. When to consider lung transplantation for COVID-19. Lancet Respir Med 2020;8:944-6.

165.Available online: https://www.fda.gov/emergencypreparedness-and-response/coronavirus-disease-2019covid-19/pfizer-biontech-covid-19-vaccine

166. Available online: https://www.fda.gov/emergencypreparedness-and-response/coronavirus-disease-2019covid-19/moderna-covid-19-vaccine 